\title{
Myeloid transformation by MLL-ENL depends strictly on C/EBP
}

\author{
Radoslaw Wesolowski ${ }^{1, *}$, Elisabeth Kowenz-Leutz ${ }^{1, *}$, Karin Zimmermann ${ }^{1} \uparrow$, Dorothea Dörr ${ }^{1}$, , Maria Hofstätter $^{1,} \dagger$, \\ Robert K Slany², Alexander Mildner ${ }^{1}$ (D), Achim Leutz ${ }^{1,3}$ (D)
}

\begin{abstract}
Chromosomal rearrangements of the mixed-lineage leukemia gene MLL1 are the hallmark of infant acute leukemia. The granulocyte-macrophage progenitor state forms the epigenetic basis for myelomonocytic leukemia stemness and transformation by MLL-type oncoproteins. Previously, it was shown that the establishment of murine myelomonocytic MLL-ENL transformation, but not its maintenance, depends on the transcription factor C/EBP $\alpha$, suggesting an epigenetic hit-and-run mechanism of MLLdriven oncogenesis. Here, we demonstrate that compound deletion of Cebpa/Cebpb almost entirely abrogated the growth and survival of MLL-ENL-transformed cells. Rare, slow-growing, and apoptosis-prone $M L L-E N L$-transformed escapees were recovered from compound Cebpa/Cebpb deletions. The escapees were uniformly characterized by high expression of the resident Cebpe gene, suggesting inferior functional compensation of $\mathrm{C} / \mathrm{EBP} \alpha / \mathrm{C} /$ EBP $\beta$ deficiency by $C / E B P \varepsilon$. Complementation was augmented by ectopic C/EBP $\beta$ expression and downstream activation of IGF1 that enhanced growth. Cebpe gene inactivation was accomplished only in the presence of complementing C/EBP $\beta$, but not in its absence, confirming the Cebpe dependency of the Cebpa/Cebpb double knockouts. Our data show that MLL-transformed myeloid cells are dependent on C/EBPs during the initiation and maintenance of transformation.
\end{abstract}

DOI 10.26508/Isa.202000709 | Received 19 March 2020 | Revised 22 October 2020 | Accepted 23 October 2020 | Published online 3 November 2020

\section{Introduction}

Mixed-lineage leukemia (MLL) represents an aggressive pediatric cancer of the blood, with features of acute lymphoblastic leukemia and acute myeloid leukemia (AML). Chromosomal translocations at $11 q 23$ are predominant in $M L L$ and fuse the $\mathrm{N}$-terminal part of the Trithorax-like MLL1/KMT2A methyltransferase to multiple partner proteins (Shilatifard, 2012; Slany, 2016). MLL-induced AML may originate from hematopoietic stem cells (HSCs) and/or an early progenitor state and involve the establishment of leukemic stem cells (LSCS) that maintain lineage plasticity and an intermediate lymphoid-myeloid immunophenotype (Daigle et al, 2011; Goardon et al, 2011; Chen et al, 2013; Krivtsov et al, 2013). Despite recent advances in understanding the molecular mechanism of the disease, therapy of $M L L$ translocation-induced leukemia remains a clinical challenge.

The prevalent leukemic $M L L$ translocations entail genes encoding components of the super elongation complex, including $E N L$, AF9, and AF4. Both MLL-ENL and MLL-AF4 represent potent fusion oncoproteins that experimentally transform murine bone marrow cells in vitro (Smith et al, 2011). Mechanistically, MLL fusion oncoproteins stimulate the expression of target genes, including critical genes of the HOXA cluster, by co-recruiting the DOT1L complex and by promoting DNA polymerase II pause release and the elongation phase of gene transcription (Okada et al, 2005; Krivtsov \& Armstrong, 2007; Krivtsov et al, 2013). Deregulated expression of the MLL target genes Hoxa9 and Meis1 partially recapitulate leukemogenic self-renewal and eventually cause experimental leukemogenesis (Collins \& Hess, 2016b).

C/EBP (CCAAT enhancer-binding protein) family members are transcription factors that may function as activators and repressors depending on the cellular and molecular context and the expression status of the C/EBP protein isoforms (Zahnow, 2002; Nerlov, 2004; Johnson, 2005). C/EBPa, a master regulator of granulocyte-macrophage progenitor (GMP) biology, is also of central importance to leukemic myelomonocytic transformation. $\mathrm{C} / \mathrm{EBP} \alpha$ controls the transition from common myeloid progenitors to GMPs and prevents exhaustion of the HSC compartment (Zhang et al, 2004). C/EBP $\alpha$-deficient progenitors resist transformation by MLL-ENL, MLL-AF9, MOZ-TIF2, and Hoxa9/Meis1. Interestingly, after the establishment of MLL-ENL transformation, C/EBP $\alpha$ can be removed genetically, whereas the malignant phenotype persists (Ohlsson et al, 2014). These findings suggest that, in the presence of C/EBP $\alpha$, a "hit-and-run"-type MLL transformation consolidates an epigenetic state that is maintained in the absence of the initial

\footnotetext{
${ }^{1}$ Max Delbrück Center for Molecular Medicine, Berlin, Germany ${ }^{2}$ Department of Genetics, Friedrich-Alexander University Erlangen-Nürnberg, Erlangen, Germany ${ }^{3}$ Institute of Biology, Humboldt University of Berlin, Berlin, Germany
}

Correspondence: aleutz@mdc-berlin.de

*Radoslaw Wesolowski and Elisabeth Kowenz-Leutz contributed equally to this work

tKarin Zimmermann, Dorothea Dörr, and Maria Hofstätter contributed equally to this work 

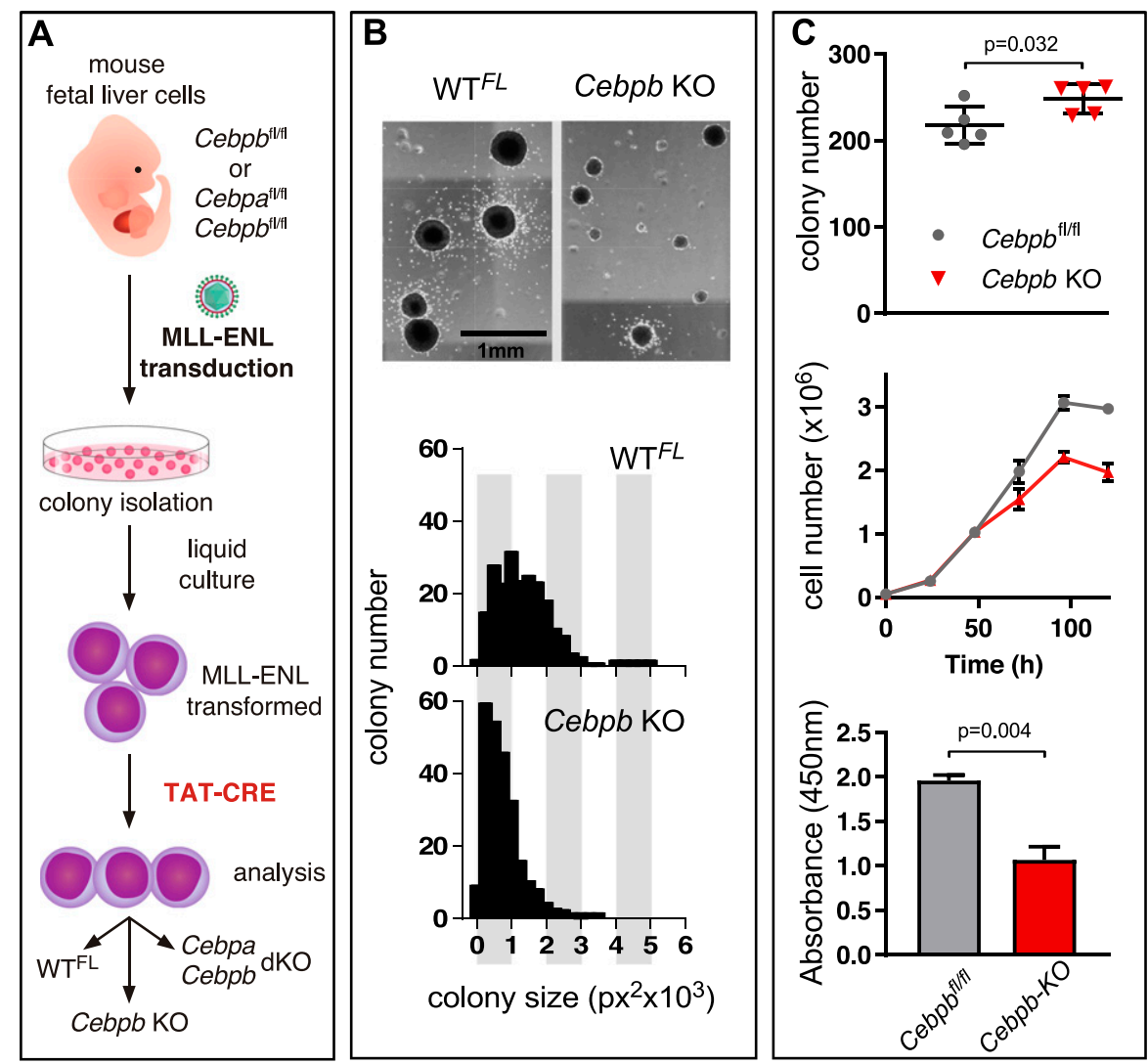

Figure 1. Cebpb Deletion in MLL-ENL-Transformed Cells.

(A) Schematic illustration of murine tissue culture MLLENL leukemia model. Top to bottom: Murine fetal liver cells from WT $T^{\mathrm{FL}}$ animals were transduced with MLLENL and selected with G418 for $14 \mathrm{~d}$ in liquid culture. Subsequently, the cells were seeded in semi-solid methylcellulose medium. Single colonies were isolated, expanded in liquid culture, and assessed for MLL-ENL integration. Next, the cells were treated with TAT-Cre recombinase to remove floxed Cebp alleles. Gene excision was determined by PCR (see Fig S1B). (B) Top: representative microscopic scans of semi-solid methylcellulose cultures with $\mathrm{WT}^{\mathrm{FL}}$ and Cebpb KO colonies. Cells were seeded at a density of 5,000 cells per 35-mm well, and colonies were scored after $10 \mathrm{~d}$. Bottom: colony size distribution (see also Fig S1C). (c) Top: $\mathrm{WT}^{\mathrm{FL}}$ and Cebpb KO colonies in semi-solid methylcellulose medium. Middle: Growth curves of $\mathrm{WT}^{\mathrm{FL}}$ and Cebpb KO colonies. Bottom: WST-1 assay showing the effect of Cebpb removal on MLL-ENL-transformed cells. Values are the mean \pm SD (two-tailed Mann-Whitney U test, $\left.{ }^{* *} P<0.005\right)$.

inducing transcription factor C/EBP $\alpha$ (Roe \& Vakoc, 2014). Alternatively, other C/EBP family members that have not been examined or that have remained undetected may be involved in maintaining the myelomonocytic and transformed state.

Here, we considered the role of $C / E B P \beta$ in maintaining the myeloproliferative $M L L$-ENL-transformed state. Using a somatic genetics approach, we show that the viability and proliferation of $M L L-E N L$-transformed mouse myeloblasts were impaired by removing $C / E B P \beta$ and were almost entirely abrogated by compound deletion of the Cebpa and Cebpb genes. Strikingly, all of the few surviving Cebpa/Cebpb-deficient MLL-ENL-transformed clones consistently expressed C/EBPE. Our data suggest that both the initiation and the maintenance of $M L L-E N L$ transformation depend on transcription factors of the C/EBP family and imply a therapeutic opportunity in interfering with the C/EBP dependency of MLL transformation.

\section{Results}

\section{Removing C/EBP $\beta$ slows the growth of MLL-ENL-transformed cells}

Experimentally induced murine leukemogenesis and acquisition of the LSC state by the MLL-ENL, MLL-AF9, and MOZ-TIF2 oncogenes depend on $\mathrm{C} / \mathrm{EBP} \alpha$ that induces myeloid commitment, or in the absence of $\mathrm{C} / \mathrm{EBP} \alpha$, on the alternative establishment of the GMP state (Ye et al, 2015). This suggests that establishment of the GMP phenotype is sufficient and subsequently epigenetically memorized, in concordance with transformation by MLL-ENL. However, the alternative induction of the GMP state in the absence of C/EBP $\alpha$ requires C/EBP $\beta$ (Hirai et al, 2006; Manz \& Boettcher, 2014). This raises the possibility that $C / E B P \beta$ may be involved in maintaining the LSC state and the leukemic process.

To distinguish between these possibilities, murine fetal liver cells derived from conditional Cebpb $b^{\mathrm{fl} / \mathrm{fl}}$ or Cebpa $a^{\mathrm{fl} / \mathrm{fl}} / \mathrm{Cebpb}^{\mathrm{fl} / \mathrm{fl}}$ (designated $\mathrm{WT}^{\mathrm{FL}}$ ) mice were retrovirally transformed by the $M L L$ ENL oncogene, as outlined in Fig 1A. Briefly, MLL-ENL-transduced liver cells were seeded in methylcellulose medium containing cytokines (IL-3, IL-6, and stem cell factor [SCF]), and the emerging transformed colonies were isolated after 10-14 $\mathrm{d}$ and expanded in cytokine-supplemented liquid medium. MLL-ENL transformation was evident by the stable growth of immortalized cells that could be propagated in the presence of IL-3. Cytofluorometric analysis showed that the majority of cells expressed myeloid lineage surface antigens (CD16/32 and CD11b), and that $>25 \%$ of the transformed populations also expressed c-Kit, a marker of HSC and early progenitor cells (Fig S1A), suggesting a progenitor/GMP-type phenotype, in agreement with published data (Somervaille \& Cleary, 2006). After myeloid cell transformation had been completed, MLL-ENL clones were treated with cell membrane-permeable recombinant TAT-Cre (Brown \& Byersdorfer, 2017) to determine the biological effect of Cebpb gene deletion on transformation (Fig S1B). Fig 1B and C show that removing Cebpb from the MLL-ENL-transformed progenitors had 
little effect on total colony numbers; however, the secondary colonies derived from MLL-ENL C/EBP $\beta$ KO cells were smaller than the colonies derived from MLL-ENL cells with an intact Cebpb allele (Figs $1 \mathrm{~B}$ and S1C). Cells derived from Cebpb KO cells showed decreased growth rates and diminished metabolism and viability in culture medium containing IL-3 (Fig 1C, cell counts and WST-1 to formazan conversion) as compared with the wild-type $\mathrm{WT}^{\mathrm{FL}} M L L-E N L$-transformed cells, in accordance with attenuated growth in semi-solid and liquid cultures. We conclude that, although Cebpb is not essential for the clonogenicity of MLL-ENL-transformed cells, it enhances their proliferation and viability.

\section{Simultaneous deletion of Cebpa/Cebpb inhibits MLL-ENL-transformed cell proliferation}

To generate compound Cebpa/Cebpb KO cells, two parental Ceb$p a^{\mathrm{fl} / \mathrm{fl}} / \mathrm{Cebp}^{\mathrm{fl} / \mathrm{fl}}$ MLL-ENL clones were infected with a retrovirus encoding a conditional Cre recombinase, and Cebp allele deletion was monitored by PCR. Cre-mediated gene deletion was readily observed; however, even after prolonged Cre recombinase activation over $5 \mathrm{~d}$, we failed to delete all four Cebp alleles over numerous attempts (data not shown). In an alternative approach, four parental Cebpa fl/fl $/ \mathrm{Cebpb}^{\mathrm{fl} / \mathrm{fl}}$ MLL-ENL clones were treated with recombinant TAT-Cre, which also resulted in allelic Cebp heterozygosity (Brown \& Byersdorfer, 2017). Clones with partial Cebp deletions were then pooled, expanded in mass culture (to $\sim 4 \times 10^{6}$ cells), and re-treated with cell-permeable TAT-Cre recombinase to force deletion of the remaining Cebpa/Cebpb alleles. The final round of Cre treatment resulted in a widespread crisis of cell growth and cell death. All surviving cells were directly seeded in semi-solid medium for scoring potential Cebpa / Cebpb double KO (dKO) on a clonal basis. In total, 1,056 colonies (from 1,200 to 1,300 colonies) were isolated and examined for Cebpa/Cebpb deletion. Only 14 Cebpa/Cebpb dKO subclones from two mice (2 and 12 subclones, respectively) could be identified, suggesting that the transformed MLL-ENL cells were strongly dependent on Cebpa/Cebpb gene expression.

We next performed phenotypical analysis of $\mathrm{WT}^{\mathrm{FL}}, \mathrm{Cebpb} \mathrm{KO}$, and Cebpa/Cebpb dKO cells by flow cytometry (Fig 2). We detected no differences in the frequencies of CD11b+ or Ly6C+ cells between the $\mathrm{WT}^{\mathrm{FL}}$ and Cebpb KO cells, suggesting that the deletion of Cebpb was compatible with maintaining the progenitor phenotype. Cebpb KO cells, however, showed diminished development of mature Ly6G+ neutrophils, whereas differentiation into CD115+ monocytes or macrophages in vitro was unaffected (Fig 2A). In contrast, compound deletion of Cebpa and Cebpb led to reduced CD11b and Ly6C reactivity, indicating a more immature or neomorphic phenotype (Fig 2A). Accordingly, neither Ly6G+ neutrophils nor CD115+ monocytes or macrophages could be derived from the Cebpa/Cebpb dKO cells (Fig 2A). Analysis of the early and late apoptotic stages in the $\mathrm{WT}^{\mathrm{FL}}$, Cebpb KO, and Cebpa/Cebpb dKO clones showed that deleting Cebpb and Cebpa/Cebpb partially and severely enhanced the apoptosis rate, respectively (Fig 2A, right). Next, we analyzed the cell proliferation rate by fluorescent CFSE dye dilution using flow cytometry. As shown in Fig 2B, cells from all genotypes were characterized by high proliferation rates. However, both single Cebpb and compound
Cebpa/Cebpb dKO cells showed reduced proliferation as compared with the $\mathrm{WT}^{\mathrm{FL}}$ cells.

Histological staining of cytospins of $\mathrm{WT}^{\mathrm{FL}}$, Cebpb KO, and Cebpal Cebpb dKO cells are shown in Fig $2 \mathrm{C}$. WT ${ }^{\mathrm{FL}}$ cells characteristically exhibited a predominant monoblastic/myeloblastic appearance, sometimes with kidney-shaped nuclei, relatively pale cytoplasm, and few, mostly diffuse cytoplasmatic granules. Cebpb KO cells displayed a similar cytoplasm/nucleus ratio to $W T^{\mathrm{FL}}$ cells, with early monocytic/myelocytic appearance, some vacuoles, and most typically, azurophilic granules in the cytoplasm. The Cebpa/Cebpb dKO cells had a smaller cytoplasm/nucleus ratio, with more darkly stained cytoplasm and frequently hyposegmented nuclei. These data suggest that the different genotypes are also reflected in distinct early myelomonocytic phenotypes.

Comparative serial replating of the $\mathrm{WT}^{\mathrm{FL}}$, Cebpb KO, and Cebpal Cebpb dKO cells revealed a steady increase in the clonogenicity of the $\mathrm{WT}^{\mathrm{FL}}$ and Cebpb KO cells and a decline in that of the Cebpal Cebpb dKO cells (Fig 2D), suggesting enrichment for transformed stem cells in the $\mathrm{WT}^{\mathrm{FL}}$ and Cebpb KO cells and the loss of stemness in the Cebpa/Cebpb dKO cells during replating. The characteristic heterogeneous appearance of the compact and disperse $\mathrm{WT}^{\mathrm{FL}}$ colonies and more uniform, round, and compact Cebpb KO colonies was maintained during replating, whereas Cebpa/Cebpb dKO colonies continuously declined during replating and ceased growth beyond the fourth replating (Fig 2E). However, differences in the colony-forming capacity between the $\mathrm{WT}^{\mathrm{FL}}$ and Cebpb KO cells became evident after partial withdrawal of cytokines (Fig 2F, growth in IL-3 medium), revealing that the Cebpb KO cells were more dependent on the standard cytokine mix (IL-3, SCF, IL-6, and GMCSF) than the $\mathrm{WT}^{\mathrm{FL}}$ cells.

\section{Endogenous C/EBPE compensates for C/EBP $\alpha$ and C/EBP $\beta$ deficiency in MLL-ENL-transformed cells}

Related gene products may functionally compensate for distinct deleted genes, and obscure otherwise severe phenotypes. In particular, this can be observed in gene families that share evolutionarily conserved origins, such as the C/EBP family (El-Brolosy \& Stainier, 2017). Therefore, we wondered about the compensatory mechanisms that may have occurred in the Cebpa/Cebpb dKO MLLENL clones to permit their survival. RNA sequencing (RNA-seq) analysis of two randomly chosen dKO clones derived from different animals confirmed the absence of Cebpa and Cebpb expression (Fig 3A). Strikingly, both dKO MLL-ENL-transformed clones showed up-regulated Cebpe gene expression, whereas Cebpd expression remained largely unchanged in the $W T^{\mathrm{FL}}$ and $\mathrm{dKO}$ cells. These data suggest that the activation of Cebpe may compensate for the loss of Cebpa/Cebpb. Accordingly, we examined all 14 recovered dKO clones for expression of the C/EBP family members by protein blotting. Fig $3 \mathrm{~B}$ shows that all $\mathrm{dKO}$ clones strongly expressed the C/EBPE protein, whereas only small and inconsistent changes were observed in C/EBPS, C/EBPY, and C/EBPS protein levels. These data are in line with previous findings showing that ectopic expression of $C / E B P \varepsilon$, similarly to $C / E B P \beta$ but unlike $\mathrm{C} / \mathrm{EBP} \alpha$, is compatible with the proliferation of GMP-like progenitors (Cirovic et al, 2017). 

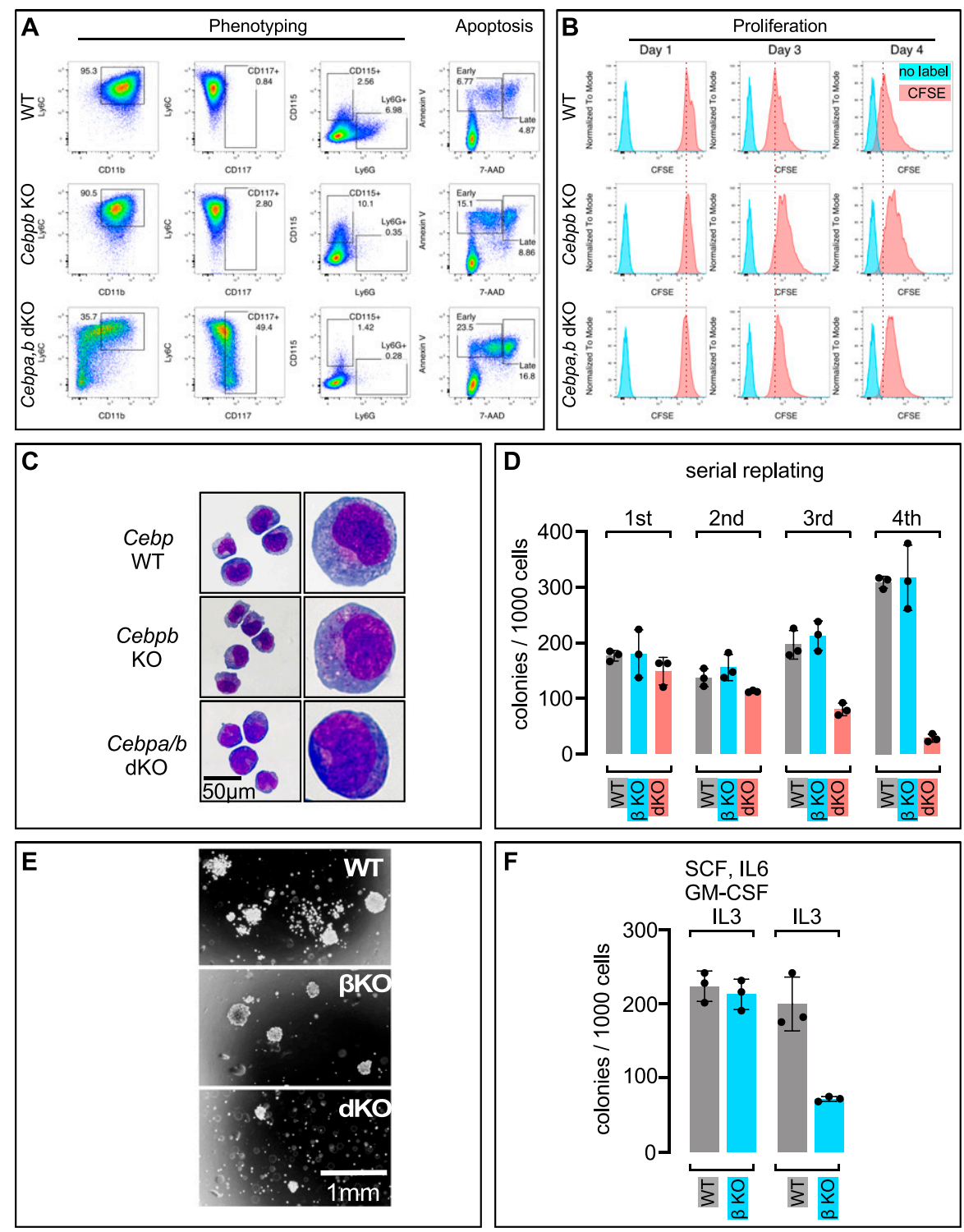
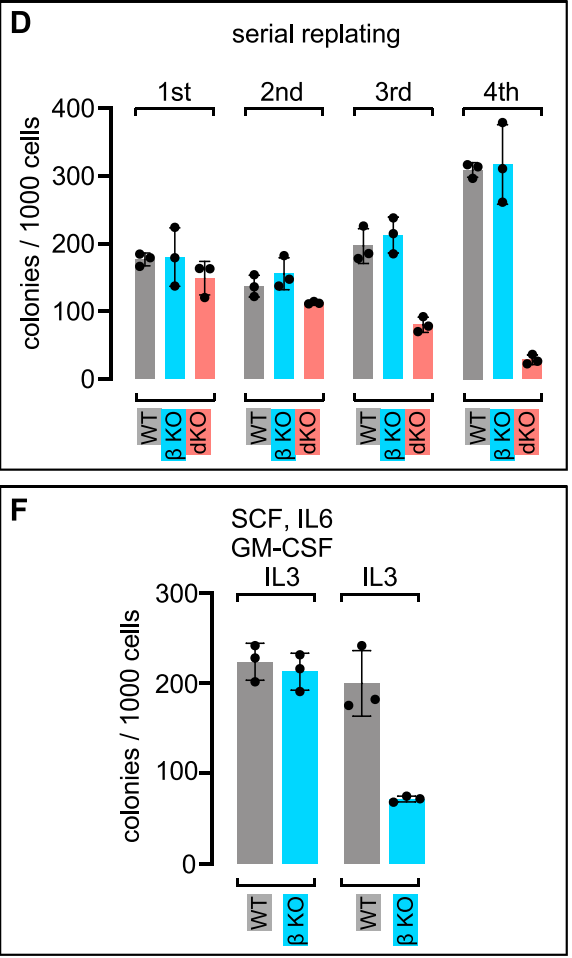

Figure 2. Characterization and comparison of MLLENL-transformed $\mathrm{WT}^{\mathrm{FL}}, \mathrm{C} / \mathrm{EBP} \beta \mathrm{KO}$, and $\mathrm{C} / \mathrm{EBP} \alpha / \mathrm{C} /$ EBP $\beta$ dKO cells.

(A) Flow cytometric phenotyping of $\mathrm{WT}^{\mathrm{FL}}$, Cebpb KO, and Cebpa/Cebpb dKO cells using CD11b, Ly6C, CD117,

CD115, and Ly6G markers (left panel). Apoptosis was examined via annexin $\mathrm{V}$ staining in combination with 7-AAD (right panel). Two independent experiments were performed, yielding similar results. (B) Analysis of frequency of cell division using CFSE in flow cytometry. Cell types as in A and cells were analyzed 1, 3, and $4 \mathrm{~d}$ after CFSE loading. Two independent experiments were performed, yielding similar results. (C) Cytospins were prepared from exponentially growing cell types and stained with Giemsa/eosin. Micrographs were taken from small groups of cells (left) to show uniformity and from enlarged single cells (right) to show differences in subcellular features. (D) Serial replating in methylcellulose/Iscove's DMEM supplemented with IL-3, stem cell factor, GM-CSF, and IL-6. Cells were seeded in triplicate, grown for $7 \mathrm{~d}$, and colonies were counted before reseeding at 5,000 cells/well. Two independent experiments and for third and fourth replating three experiments were performed, yielding similar results. (E) Micrographs of colonies from fourth replating. (F) Cells from the third replating round were seeded in semi-solid medium supplemented with the complete cytokine cocktail or IL-3 only, as indicated. Colonies were counted after $7 \mathrm{~d}$. Three independent experiments were performed, yielding similar results.
All 14 recovered Cebpa/Cebpb dKO clones grew slowly in liquid culture and had increased apoptosis, as compared with the $W T^{F L} M L L$-ENL-transformed cells (compare with Fig 2A, right), suggesting incomplete functional compensation by $\mathrm{C} / \mathrm{EBP} \varepsilon$. To determine whether distinct C/EBP isoforms could rescue $M L L-$ ENL-transformed cell growth, isoforms of C/EBP $\alpha$ ( 42 and p30) or C/EBP $\beta$ (LAP*, LAP, and LIP) were retrovirally transferred and subsequently enriched for co-expression of GFP, as shown in Fig 4A. As expected, growing cells that expressed the proliferation-suppressive C/EBP $\alpha$ p42 isoform could not be recovered, and the few $\mathrm{GFP}^{+}$sorted cells that grew out failed to express the $\mathrm{p} 42$ protein, confirming successful retroviral transduction but failure of genetic complementation by C/EBP $\alpha$ p42. Growing cells were obtained for all other constructs (Fig $4 \mathrm{~A}$ ), and their proliferation rates, clonogenicity, and viability were assessed. Colony formation of the parental dKO cells was partially rescued by the C/EBP $\alpha$ p30 isoform (Fig 4B-D), and to a higher extent by the C/EBP $\beta$ LAP* isoform, whereas the C/EBP $\beta$ LAP and C/EBP $\beta$ LIP isoforms displayed intermediate and no discernible complementation capacity, respectively (Figs $4 \mathrm{E}-\mathrm{G}$ and $\mathrm{S} 2$ ). In summary, the C/EBP $\beta$ LAP* isoform, and in part, the C/EBP $\beta$ LAP or C/EBP $\alpha$ p30 isoforms, restored dKO $M L L-E N L$-transformed cell proliferation (Fig $4 \mathrm{~B}$ and $\mathrm{E}$ ) and viability (Fig 4C and F).

Next, we examined the role of C/EBPE in Cebpa/Cebpb dKO MLL$E N L$ cells that expressed high levels of endogenous C/EBPE, termed $C / E B P \varepsilon^{+}$, by RNA interference strategies. However, the fragile dKO $M L L-E N L C / E B P \varepsilon^{+}$cells did not tolerate the small interfering RNA treatment, and various conditionally inducible, retrovirally delivered short hairpin RNAs failed to down-regulate C/EBPE reproducibly (data not shown). The data may suggest that triple deletion of the Cebpa, Cebpb, and Cebpe genes is incompatible with cell survival. Interestingly, we observed that expression of the endogenous C/EBPE ceased after extended cultivation of MLL-ENL dKO cells that were complemented with the C/EBP $\beta$ isoforms LAP*, 


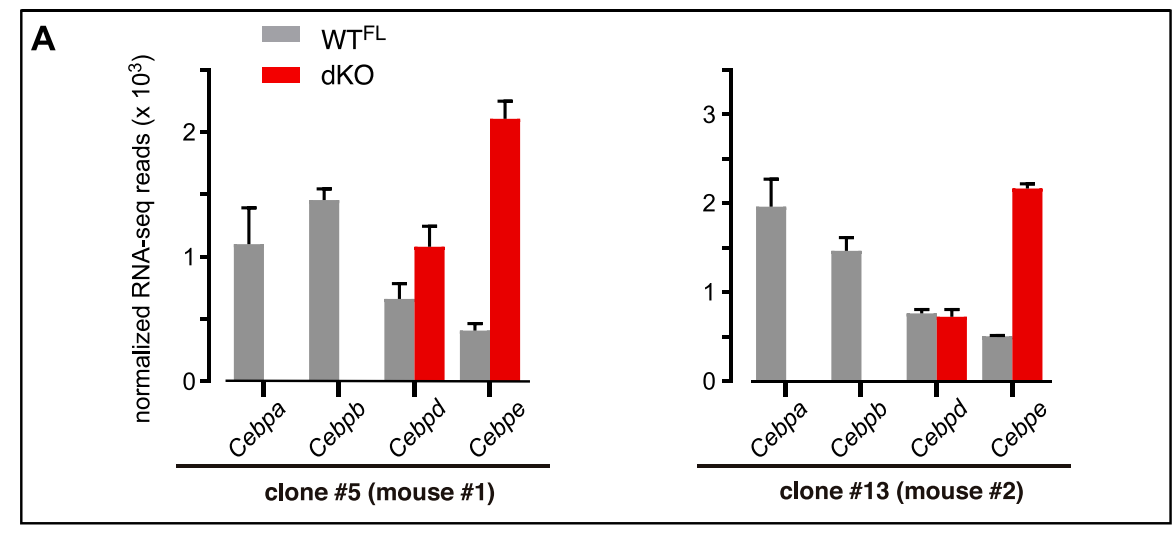

B

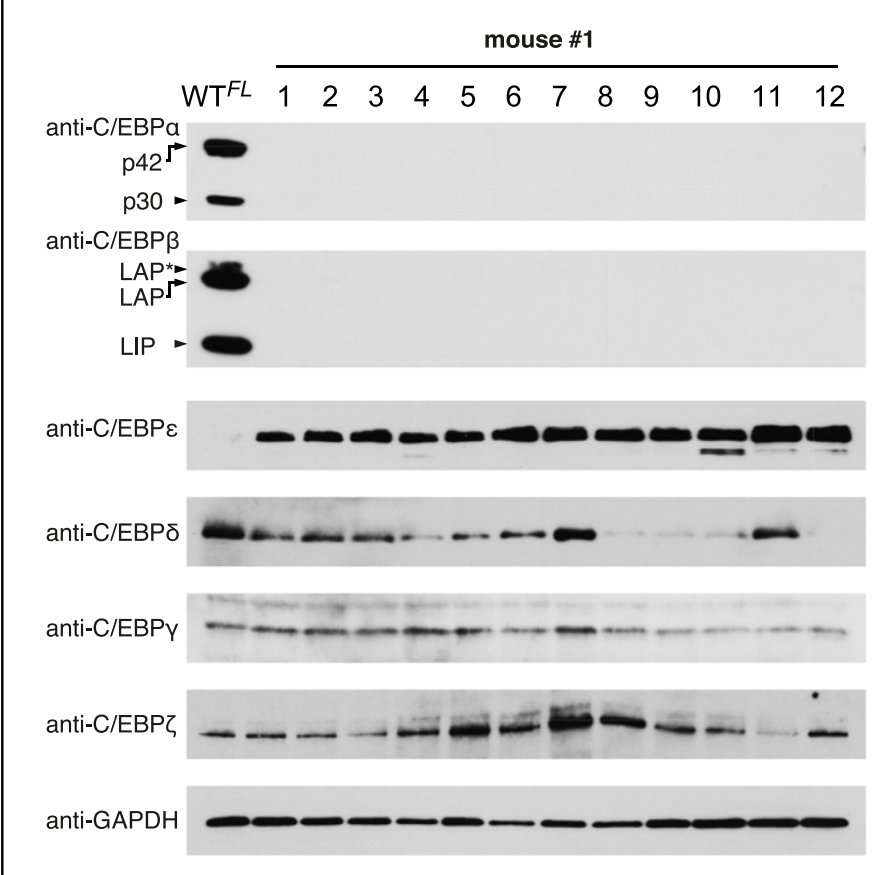

Figure 3. MLL-ENL-Transformed dKO Clones Express C/EBPE.

(A) Data showing normalized RNA-seq read counts for indicated genes of the Cebp family in $W T^{\mathrm{FL}}$ (gray) and two independent Cebpa/Cebpb dKO MLLENL-transformed cell clones (red) derived from different mice. RNA-seq was performed in triplicates. (B) Immunoblots show the expression of resident C/ EBP family proteins from $W T^{\mathrm{FL}}$ and dKO transformed MLL-ENL cells. The panel summarizes C/EBP family protein expression in all $14 \mathrm{dKO}$ clones from two different mice (clone \#1-12, mouse 1; clone \#13 and \#14, mouse 2). and to a lesser extent with LAP, but not with LIP (Fig 5A). Based on the observation of an inverse correlation between resident $\mathrm{C} / \mathrm{EBP} \varepsilon^{+}$ protein levels before and after ectopic C/EBP $\beta$ LAP* expression (Fig $5 A)$, we explored the mutability of Cebpe in dKO MLL-ENL cells in the presence or absence of ectopically expressed C/EBP $\beta$ LAP*, as outlined in Fig 5B. Briefly, targeted deletion of resident Cebpe by Cas9 was examined after transduction of dKO cells with either empty control or C/EBP $\beta$ LAP* retrovirus in parallel, both expressing GFP as a marker. GFP ${ }^{+}$cells from both approaches were sorted, expanded, and infected with the same batch of a genome editing vector, encoding blue fluorescent protein (BFP) as a marker and Cas9 plus guide RNAs ( Li et al, 2016; Henriksson et al, 2019), targeting Cebpe exon 1. After infection, sorted $\mathrm{BFP}^{+}$cells were expanded, seeded in semi-solid medium, and individual colonies were isolated from both vector control and C/EBP $\beta$ LAP* expressing cells (Fig 5B).
In comparison to vector control cultures that showed many abortive small colonies, augmented colony formation and proliferation were already discernible at an early stage during colony formation in C/EBP $\beta$ LAP*-complemented dKO cells (data not shown). After single colonies had been isolated, proliferation in liquid culture was discontinued in $35.9 \%$ of the vector control clones ( $N=79 / 220$ clones), but only $17.8 \%$ ( $N=32 / 180$ clones) of the $\mathrm{C} / \mathrm{EBP} \beta$ LAP* supplemented dKO clones were abortive (Fig 5C). Only $12.3 \%(27 / 220)$ of the vector controls, yet $48.9 \%$ (88/180) of the C/EBP $\beta$-LAP* dKO clones showed robust growth in liquid culture. Among the vector control clones, all 27 properly growing control clone isolates and 31 (out of 88) randomly chosen C/EBP $\beta$ LAP*complemented clones were expanded in liquid culture. As shown by protein blotting (Fig 5D), each of the five $L A P^{*}$-dKO and five vector controls showed reciprocal expression of LAP* and C/EBPE. Analysis of the genomic Cebpe status (Fig 5E) showed that 80\% (16/27 clones) 


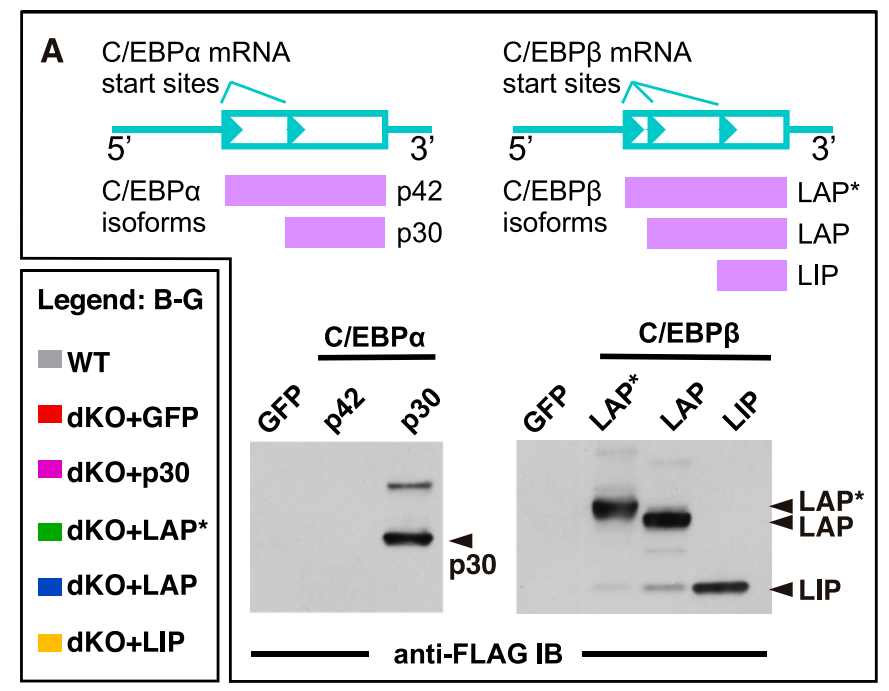

B

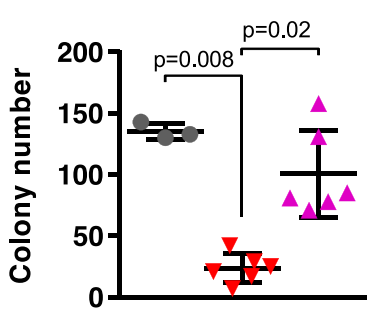

C

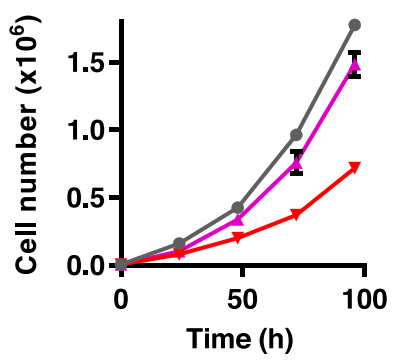

D

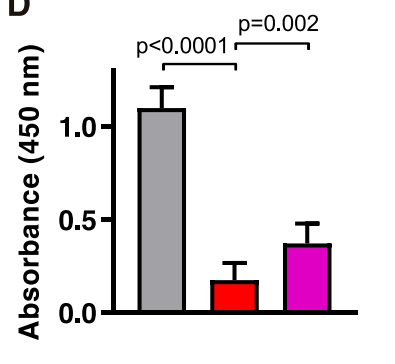

E

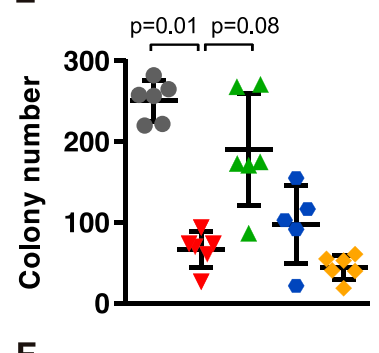

$\mathbf{F}$

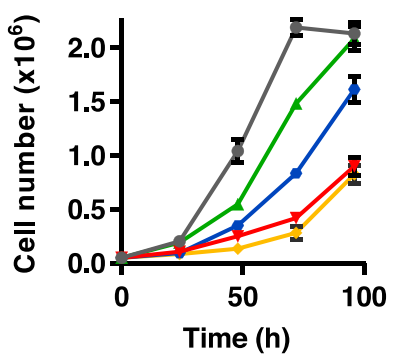

G

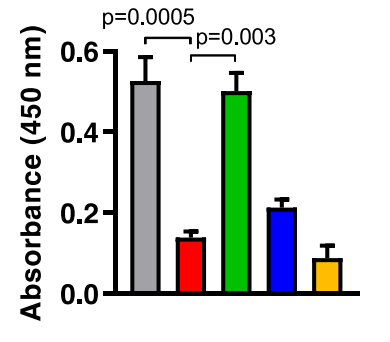

Figure 4. Complementation of Growth Defects by C/EBP $\alpha$ and C/EBP $\beta$ Isoforms in MLL-ENL-Transformed dKO Cells.

(A) Transcripts of Cebpa and Cebpb with alternative translation initiation sites (arrowheads; cyan) giving rise to different protein isoforms (indicated underneath, purple, and on the right) as examined in Fig 4B. Below: C/EBP expression controls of retrovirally expressed FLAG-tagged C/EBP isoforms expressed in MLL-ENL-transformed dKO cells. Cell lysate immunoblots (IB) were probed with anti-FLAG. GFP: negative control retrovirus; C/EBP $\alpha$ isoforms $p 42$, p30; C/EBP $\beta$ isoforms LAP*, LAP, and LIP. (B, C, D) C/EBP $\alpha$ complementation: (B, C, D). (E, F, G) C/EBP $\beta$ complementation: (E, F, G). (B, C, D, E, F, G) Left, bottom insert:

of the vector control clones retained the WT Cebpe genotype, and only two showed indel frameshift mutations (see below). In contrast, $74 \%$ (20/31 clones) of the C/EBP $\beta$ LAP*-complemented clones showed biallelic frameshift indels and/or large deletions. Importantly, 7/27 vector control clones but only 2/31 of LAP* clones had in-frame mutations. Both $\mathrm{C} / \mathrm{EBP} \beta \mathrm{LAP}^{*}$-complemented in-frame mutations were associated with frameshift indels in the second Cebpe allele, whereas both frameshift indels of the vector control cells retained either a WT or an in-frame deletion in the second allele, respectively. Most remarkably, all in-frame mutations affected negative regulatory C/EBPE regions I or II (Fig 5F), previously described to restrain C/EBPE activity (Angerer et al, 1999). Taken together, these data show that biallelic Cebpe inactivation in $\mathrm{dKO}$ cells occurred only in the presence of C/EBP $\beta$ LAP*, but not in its absence. In the absence of ectopically expressed C/EBP $\beta$ LAP*, either the WT genotype persisted, or alternatively, in-frame deletions affecting negative regulatory $\mathrm{C} / \mathrm{EBP} \varepsilon$ regions were selected, strongly supporting the requirement of functional C/EBPE in the absence of Cebpa/Cebpb. Accordingly, we conclude that myelomonocytic MLL-ENL transformation remains dependent on C/EBP and that C/EBPE may partially compensate for the loss of Cebpal cebpb.

\section{C/EBPs coordinate the expression of the MLL-ENL/Hoxa target genes}

The combined deletion of Cebpa and Cebpb led to widespread leukemic cell death and selected for compensatory expression of $\mathrm{C} / \mathrm{EBP} \varepsilon$ in $\mathrm{dKO}$ clones, suggesting that maintenance of the transformed cell identity is C/EBP-dependent. To test this hypothesis, we performed RNA-seq (two clones, \#5, \#13, in triplicates) of the MLLENL-transformed cell transcriptomes before and after compound Cebpa/Cebpb deletion. Deleting Cebpa/Cebpb resulted in the up-regulation of 2066 (clone \#5) and 2,517 (clone \#13) genes (755 genes overlapping), respectively, and the down-regulation of 2,447 (clone \#5) and 2,702 (clone \#13) genes (1,024 genes overlapping),

Color code of complementation assays, as shown in (B, C, D, E, F, G). (B) Number of $M L L-E N L$-transformed colonies derived from $W T^{\mathrm{FL}}$ or dKO cells with and without complementation by retrovirally encoded Cebpa p30. Cells were seeded at 500 cells per 35-mm well. The significance of the change in colony number between the $\mathrm{dKO}$ and other groups was evaluated with the Kruskal-Wallis test, followed by the post hoc Dunn test. (C) Growth curves of $W T^{\mathrm{FL}}$, dKO, and dKO cells complemented with $\mathrm{p} 30 \mathrm{C} / \mathrm{EBP} \alpha$. (D) WST-1 assay of WT ${ }^{\mathrm{FL}}, \mathrm{dKO}$, and dKO cells complemented with $\mathrm{p} 30 \mathrm{C} / \mathrm{EBP} \alpha$. Values are the mean $\pm \mathrm{SD}$. The significance of the change in metabolism level between the dKO and other groups was evaluated with the Kruskal-Wallis test, followed by the post hoc Dunn test. (B, C, D, E) Colony formation of MLL-ENL cells as in (B, C, D). Panel shows the number of MLL-ENL-transformed colonies formed in methylcellulose medium by $\mathrm{WT}^{\mathrm{FL}}, \mathrm{dKO}$, and complementation by retrovirally encoded C/EBP $\beta$ LAP*, LAP, and LIP isoforms. Cells were seeded at 500 cells per $35-\mathrm{mm}$ well. The significance of the change in colony number between the $\mathrm{dKO}$ and other groups was evaluated with the Kruskal-Wallis test, followed by the post hoc Dunn test. (F) Growth curves of MLL-ENL-transformed WT ${ }^{\mathrm{FL}}$, dKO, and LAP*-, LAP-, LIP-C/EBP $\beta$ complementation dKO cells. (G) WST-1 assay of MLL-ENL-transformed $W T^{F L}, d K O$, and LAP*-, LAP-, and LIP-C/EBP $\beta$ complementation dKO cells. Values are the mean \pm SD. The significance of the change in metabolism level between the $\mathrm{dKO}$ and other groups was evaluated with the Kruskal-Wallis test, followed by the post hoc Dunn test. 


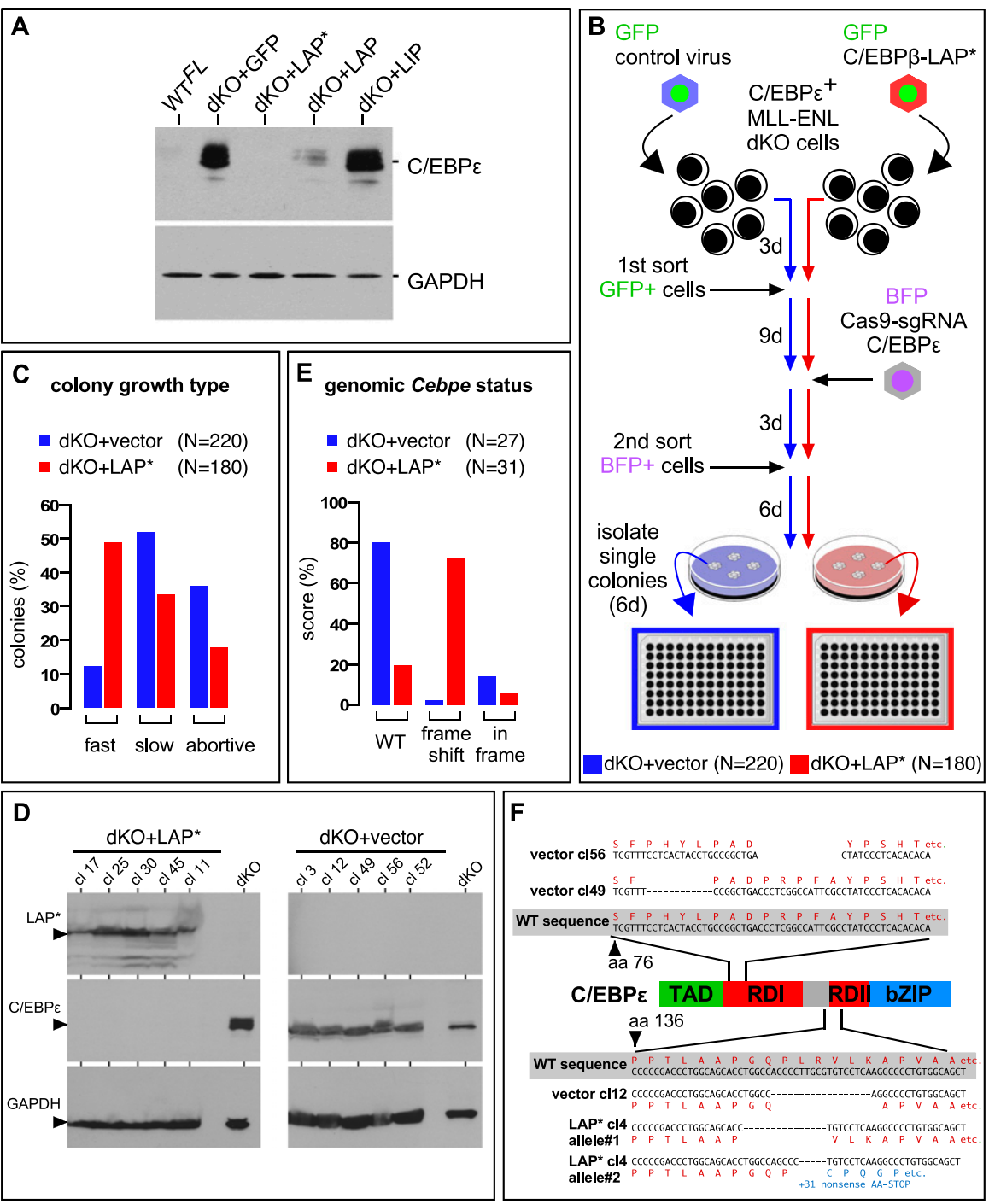

Figure 5. Examination of C/EBPE dependency of MLLENL-transformed Cebpa/Cebpb dKO C/EBP $\varepsilon^{+}$cells via genome editing.

(A) C/EBPE protein levels after prolonged growth of $\mathrm{WT}^{\mathrm{FL}}$ and dKO cells infected with control virus (GFP) or vectors encoding different C/EBP $\beta$ isoforms. (B) Scheme of Cas9-mediated genome editing. C/EBP $\varepsilon^{+}$dKO cells were infected with control virus or C/EBP $\beta$ LAP* encoding virus, both expressing GFP. After infection, cells were grown for $3 \mathrm{~d}$, sorted by flow cytometry, and $\mathrm{GFP}^{+}$cells were expanded for $9 \mathrm{~d}$. C/EBPE ${ }^{+}$dKO vector control cells and C/EBP $\beta$ LAP*-complemented cells were infected with retrovirus encoding BFP, Cas9, and guide RNAs targeting Cebpe exon 1. After $3 \mathrm{~d}$, the cells were sorted and expanded for $6 \mathrm{~d}$, and seeded in semisolid medium containing IL-3. Individual colonies were isolated and expanded in 96-well plates in liquid medium (plus IL-3). (c) Growth of isolated cells from single colonies was microscopically inspected over $1 \mathrm{wk}$ and scored as fast, slow, or abortive growth.

(D) Randomly chosen fast-growing clones from (D) were examined by protein blotting for expression of $\mathrm{C} /$ EBP $\varepsilon$ and $\mathrm{C} / \mathrm{EBP} \beta$, and GAPDH as the loading control by protein-specific antibodies, as indicated on the left. (E) Cebpe exon 1 DNA derived from 27 vector control clones and $31 \mathrm{C} /$ EBP $\beta$ LAP*-complemented clones was amplified by PCR and analyzed by Sanger sequencing and the Inference of CRISPR Edits (ICE) software tool (ice.synthego.com). (F) (Middle) Scaled schematic representation of C/EBPE showing the transactivation (TAD), regulatory (RD1 and RD2), and basic zipper (bZIP) regions. Top: examples of in-frame deletions in RD1 from two vector control clones (clones $\# 49$ and \#56). Bottom: examples of in-frame deletions in RD2 (vector control clone \#12) and one LAP*-

complemented clone (\#4) with an in-frame deletion in one C/EBPE allele and frameshift in the second allele. respectively, when a corrected $P$-value $<0.05$ was used as the cutoff (Fig 6A and Table S1).

We first investigated the impact of the combined loss of $\mathrm{C} / \mathrm{EBP} \alpha$ and $C / E B P \beta$ on the direct and indirect targets of MLL-ENL (Collins et al, 2014; Garcia-Cuellar et al, 2016). Of the 166 direct/core MLL-ENL target genes, a significant 70 genes $\left(P=2.97 \times 10^{-12}\right)$ were among the deregulated genes. Interestingly, 61 of these 70 genes had absolute fold change $(F C)<2$, including Hoxa10 and Hoxa9 $(P=0.07$ ) (Fig 6B). As many of the MLL-ENL target genes were significantly but not highly deregulated, we presumed that the high levels of surrogate C/EBPE stabilized the expression of the core MLL-ENL target genes in $\mathrm{C} / \mathrm{EBP} \varepsilon^{+} \mathrm{dKO}$. Other, more dysregulated MLL-ENL candidates ( $\mathrm{FC}>2$; $P<0.05)$ were the DOT1L/transcription initiation-sensitive genes Bahcc1 and Fut8, and the Brd4/elongation-sensitive genes Sox4 and $M p o$, which were all up-regulated, suggesting that they were partially repressed by C/EBP $\beta$ and/or C/EBP $\alpha$ (as already known for C/EBP $\alpha$-mediated Sox4 suppression [Zhang et al, 2013]). Otherwise, C/EBPE may represent a less potent inhibitor or a more potent activator of these genes (Zhang et al, 2013).
For the indirect MLL-ENL targets, removing C/EBP $\alpha$ and $C / E B P \beta$ affected the genes downstream of the transcriptional control of HOXA9/MEIS1 that had been identified after the removal of Cebpa in HOXA9/MEIS1-transformed cells (Collins et al, 2014; Collins \& Hess, 2016a, 2016b). Gene set enrichment analysis (GSEA) (Liberzon et al, 2011; Wu \& Smyth, 2012) revealed significantly deregulated HOXA9mediated gene suppression ( $P<0.05$ ) (Fig 6C), including Cpa3, Gzmb, Peg13, Mycn, Hgfac, Alox5, Gata2, Nkg7, Stx3, Cdh17, Scin, Rgs10, Havcr2, and Col18a1, but excluding the self-renewal inhibitor Cdkn2b (gene set extracted from Collins et al [2014]). The entire HOXA9/C/EBP $\alpha$ co-activated gene set was not significantly deregulated, yet the dKO cells showed increased Adra2a, Pcp4l1, Itsn1, and Igf2r expression from the HOXA9/C/EBP $\alpha$ co-activated set, whereas Adam17, Gm1110, Pde7a, Pdcd4, and Nrg2 expression were reduced.

Next, we investigated lineage restriction in the transformed cells by comparing the transcriptional landscape of $W T^{\mathrm{FL}}$ and $\mathrm{dKO}$ cells to the ImmGen database (Heng \& Painter, 2008). Compared with the $W T^{\mathrm{FL}}$ cells, the dKO cells lost some of their myeloid expression 

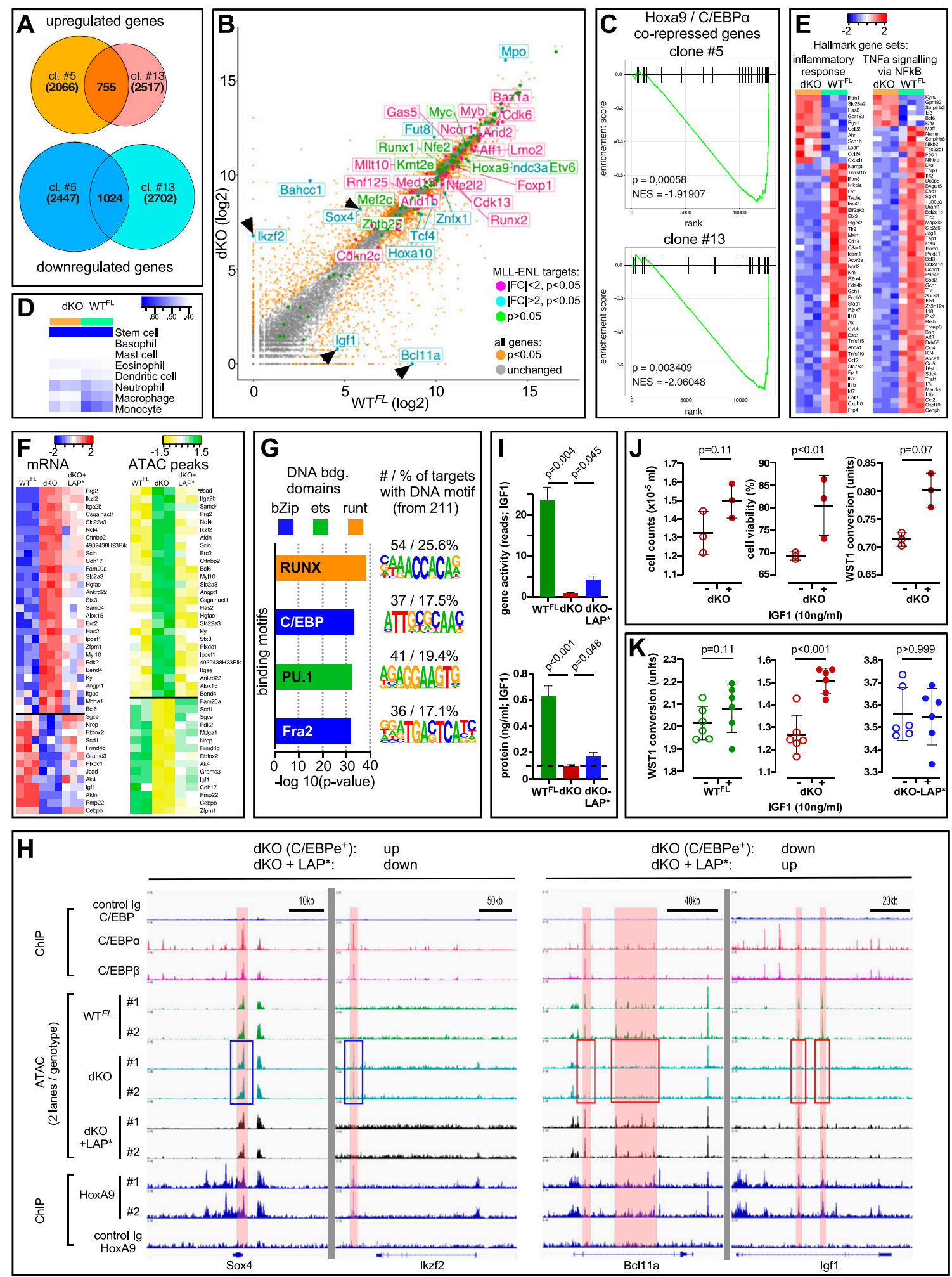

Figure 6. Molecular Genetic Profiling of MLL-ENL-Transformed dKO Cells.

(A) Venn diagrams showing the overlap between up-regulated (Benjamini-Hochberg corrected $P$-value $<0.05$ ) and down-regulated (Benjamini-Hochberg corrected $P$ value $<0.05$ ) genes in both dKO clones as determined by RNA-seq. $N=3$ per genotype. (B) Scatter plot showing dysregulation of MLL-ENL target genes, which are colored according to $P$-value and fold change. All remaining genes are colored according to their $P$-value only (see figure key). Two genes, Igf1 and Bcl11a, are included in the plot, as they are known MLL translocation targets. (C) Gene set enrichment analysis showing significant enrichment of genes co-repressed by HOXA9/C/EBP $\alpha$ among the deregulated genes. Most of these genes were up-regulated in the dKO cells. (D) Comparison of expression patterns to that of ImmGen data shows a shift in overall gene 
characteristics and showed less similarity to monocytes and macrophages (Fig 6D). Specifically, Csfir, Rel family members (Rel, Rela, and Relb), and Tgfbr2 levels were decreased in the dKO cells, supporting the pioneering role of $\mathrm{C} / \mathrm{EBP} \alpha$ and $\mathrm{C} / \mathrm{EBP} \beta$ in myeloid commitment (Wang et al, 2006; Jaitin et al, 2016; Tamura et al, 2017). However, the $\mathrm{WT}^{\mathrm{FL}}$ and $\mathrm{dKO}$ cells were similarly enriched for genes shared with HSC, highlighting the LSC state of the cells.

For a more general/unbiased approach, we performed GSEA on the hallmark gene sets of MsigDB to examine the enrichment of functional terms in the group of differentially expressed genes between the $\mathrm{WT}^{\mathrm{FL}}$ and dKO genotypes (Liberzon et al, 2011; Wu \& Smyth, 2012). Consistent with the reduced myeloid commitment observed in the dKO cells (Fig $2 \mathrm{~A}$ ), we detected strong dysregulation of the inflammatory genes, documented by significant enrichment of "hallmark inflammatory response" and "hallmark Tnfa signaling via Nfkb" $(P<0.05)$ with partially overlapping genes, in addition to an increase in stem cell transcripts (see the corresponding heat maps in Fig 6E). Altogether, these results support the premise that C/EBPE partially compensates for the loss of Cebpa/Cebpb by securing a MLL-ENL and Hoxa9 regulated core gene expression program and shifts the transformed phenotype towards an immature phenotype.

The superior growth and viability of the $\mathrm{WT}^{\mathrm{FL}}$ and $\mathrm{dKO}$-LAP* cells over Cebpa/Cebpb dKO cells was evident, affirming that compensation by C/EBPE remains incomplete. To identify ancillary MLL-ENL targets that may be involved in restoring the WT phenotype, we compared differential gene expression with the genome accessibility status using Assay for Transposase-Accessible Chromatin with sequencing (ATAC-seq) (Buenrostro et al, 2013) in the three genotypes, that is, $\mathrm{WT}^{\mathrm{FL}}$, Cebpa/Cebpb dKO, and Cebpa/Cebpb dKO complemented with $C / E B P \beta$ LAP*. Initial inspection of chromatin accessibility around the Cebpa/Cebpb loci confirmed the dKO status, whereas the ATAC peak pattern around the Cebpe locus remained unchanged, ruling out the possibility that a recombination event at the Cebpe locus may have contributed to enhanced Cebpe expression in the dKO cells (Fig $6 \mathrm{H}$ ). Focusing on genes that exhibited both, re-establishing gene expression and restoring chromatin status in dKO-LAP* cells towards WT ${ }^{\mathrm{FL}}$ status yielded a list of genes (highly correlated gene expression and chromatin status), part of which is shown in Fig 6F. Importantly, known motif search showed significant enrichment of the CEBP, ETS, and RUNX binding motifs (Fig $6 \mathrm{G}$ ) in the genomic regions determined by the full list of ATAC peaks, as described in Fig 6F. Fig $6 \mathrm{H}$ shows that, in dKO cells, the enhanced Sox 4 and Ikzf2 gene expression (Fig 6B) was associated with increased chromatin accessibility, whereas decreased Bcl11a and Igf1 gene expression was associated with decreased ATAC peak sizes, whereas ectopic expression of LAP* restored ATAC peaks to the WT conditions (Fig $6 \mathrm{H}$ ).

Open chromatin regions that were present in $\mathrm{WT}^{\mathrm{FL}}$ cells, absent in $\mathrm{dKO}$ cells, and restored in dKO-LAP* cells were identified in an intronic region of the Igf1 gene (Fig $6 \mathrm{H}$ ) that overlapped with a super-enhancer region previously identified in monocytes and liver cells (Jiang et al, 2019). Moreover, IGF1 has been described as a growth-regulatory MLL-ENL/Hoxa9/Meis1 target and as a direct $C / E B P \beta$ target gene involved in autocrine stimulation of transformed murine monocytes and in neoplasia (Pollak et al, 2004; Wessells et al, 2004; Steger et al, 2015; Collins \& Hess, 2016b). Comparison of the Igf1 RNA-seq reads confirmed Igf1 gene expression in the $\mathrm{WT}^{\mathrm{FL}}$ and $\mathrm{dKO}-\mathrm{LAP}^{*}$ cells, but not in the dKO cells (Fig 6I, top panel), and quantification by ELISA in tissue culture supernatants (Fig 6I, bottom panel) showed that IGF1 was produced by the $\mathrm{WT}^{\mathrm{FL}}$ and $\mathrm{dKO}-\mathrm{LAP}^{*}$ cells, but not by dKO cells. Adding IGF1 (10 $\mathrm{ng} / \mathrm{ml}$ ) to the culture medium increased the cell number, viability (toluidine exclusion), and metabolism (WST-1 conversion) of the dKO culture (Fig 6J) but not that of the $\mathrm{WT}^{\mathrm{FL}}$ or dKO-LAP* cultures (Fig 6K). Taken together, these data suggest that C/EBP family member- and isoform-specific regulation can differentially affect several MLL-ENL target genes. The data also confirm a C/EBP $\beta$ coregulated autocrine function of IGF1 in MLL-ENL transformation.

\section{Discussion}

Myelomonocytic commitment and differentiation into the GMP state depends on C/EBP transcription factors and is a prerequisite for the emergence of AML and LSC. Our data show that the continuous presence of C/EBP transcription factors is essential for maintaining leukemic myelomonocytic transformation by the MLLENL oncogene product of fetal liver hematopoietic progenitor cells in tissue culture.

A current concept of myeloid leukemogenesis suggests that LSC arise in committed progenitors that resemble GMP-like cells that acquire self-renewal capacity (Cozzio et al, 2003; Huntly et al, 2004; Jamieson et al, 2004; Krivtsov et al, 2006). As an inducer of the GMPlike state, it has been suggested that C/EBP $\alpha$ plays a critical role in leukemic myelomonocytic transformation. Intriguingly, once leukemic progenitor transformation is established, C/EBPa can be genetically removed, whereas the leukemic state persists (Ohlsson et al, 2014; Ye et al, 2015). Along the same lines, the initiation of oncogene-induced leukemic transformation in the absence of C/EBP $\alpha$

expression patterns, with loss of myeloid characteristics and maintenance of stem cell patterns in dKO cells indicated by Spearman correlation. (E) Heatmap of inflammatory and TNF $\alpha / N F-K B$ hallmark genes (gene sets derived from MSigDB) in WT ${ }^{\mathrm{FL}}$ and dKO cells. Both terms are significantly enriched (adjusted $P$-value $<0.05$, according to Gene set enrichment analysis). The heat maps show genes of the respective gene sets exhibiting an adjusted $P$-value $<0.05$ and an absolute fold change $>2$. Row z-score of normalized $\log _{2}$ counts. (F) Subset of the co-regulated transcriptome and genome structure as determined by RNA-seq and ATAC-seq. The whole list comprises genes that exhibit both the re-establishment of gene expression and restoration of the chromatin status in dKO-LAP* cells to WT ${ }^{\mathrm{FL}}$ status. Row Z-Score of normalized $\log _{2}$ counts. $(\mathbf{F}, \mathbf{G})$ Known motif prevalence in dKO-LAP* cells in the full set of genes shown in (F) as determined by HOMER. (H) Examples of replicate ATAC-seq data from $W_{T^{\mathrm{FL}}}$, dKO, and dKO-LAP* MLL-ENL-transformed cells indicating gain of peaks (left, blue outline) in dKO at the Sox4 and Ikzf2 loci, and loss of peaks at the Bcl11a and Igf1 loci (right, red outline). The top three lanes show C/EBP $\alpha$ and C/EBP $\beta$ chromatin immunoprecipitation (ChIP) data from MLL-AF9-transformed cells (Roe et al, 2016); the bottom three lanes show Hoxa9 ChIP data from Zhong et al (2018). (I) Igf1 gene expression (top: RNA-seq data from triplicates) and IGF1 secretion into the growth medium (bottom: ELISA data; ELISA was repeated 3 times yielding similar results) by MLL-ENL-transformed cells. (J) Response of MLL-ENL-transformed dKO cells to the addition of IGF1 to the culture medium as determined by cell counts, viability, and metabolic activity. (K) Comparison of response to IGF1 of WT ${ }^{F L}$, dKO, and dKO-LAP*complemented cells. 
can still be achieved, if concomitant emergency granulopoiesis is induced (Ye et al, 2015). These data suggest the achievement of the GMP-like state as the most critical event in leukemic transformation, regardless of how the GMP state is achieved. However, emergency granulopoiesis elicits C/EBP $\beta$ expression (Hirai et al, 2006), and gene replacement experiments have shown that $C / E B P \beta$ expressed from the C/EBP $\alpha$ locus can fully complement the hematopoietic functions of $C / E B P \alpha$, including differentiation into GMP (Jones et al, 2002). The alternative explanation for the maintenance of the leukemic state after removing $\mathrm{C} / \mathrm{EBP} \alpha$, therefore, is that $\mathrm{C} / \mathrm{EBP} \alpha$ may initially pass the "GMP baton" to $\mathrm{C} / \mathrm{EBP} \beta$, which in turn supports proliferation and maintains the transformed myeloid state.

Our data show that maintaining myeloid MLL-ENL transformation strongly depends on combined C/EBP $\beta$ and C/EBP $\alpha$ expression. The non-oncogenic dependence (Solimini et al, 2007; Nagel et al, 2016) on C/EBP transcription factors became evident from the analysis of the dKO mutants, which yielded very few clonogenic cells that consistently expressed resident C/EBPE. Genetic removal of both Cebpa and Cebpb consequently revealed a surrogate function of C/EBPE in myeloid MLL-ENL transformation. This finding is in line with several $\mathrm{KO}$ studies involving various members of the $\mathrm{C} / \mathrm{EBP} \alpha, \beta, \delta$, and $\varepsilon$ family that revealed redundant $\mathrm{C} / \mathrm{EBP}$ functions only in compound deletion mutants. Indeed, C/EBPE partially compensated for the loss of $\mathrm{C} / \mathrm{EBP} \beta$ during murine myelopoiesis and the innate immune response and was also compatible with the proliferative progenitor state (Akagi et al, 2010; Cirovic et al, 2017). Whether the rare event of C/EBPE expression in the MLL-ENLtransformed cultures may have occurred before or after Cebpa or Cebpb deletion, potentially reflecting MLL-ENL progenitor plasticity, or as a regulatory event that occurred under the selective pressure of Cebpa/Cebpb removal, remains to be determined.

The data suggest a compensatory backup function of C/EBP $\varepsilon$ in the surviving Cebpa/Cebpb dKO MLL-ENL cells that may maintain the minimal essential GMP condition in the absence of Cebpa/ Cebpb and serve as a proxy in regulating the most critical genes involved in MLL-ENL transformation. Consistently, genetic removal of C/EBPE from dKO cells by gene editing was only possible after complementation with $\mathrm{C} / \mathrm{EBP} \beta \mathrm{LAP}^{*}$, whereas uncomplemented cells only tolerated $\mathrm{C} / \mathrm{EBP} \varepsilon$ gene editing as in-frame mutations that removed parts of the negative regulatory regions of the C/EBPE protein (Angerer et al, 1999). Taken together, the results suggest the essential functions of C/EBP family members, and in particular, a privileged function of C/EBP $\beta$ LAP* in the proliferation, survival, and maintenance of the myeloid cell fate of transformed MLL-ENL cells.

Regulation of the Hox cluster target genes, including Hoxa9 and Meis1, previously emerged as a hallmark of MLL translocation leukemia, and the combined expression of Hoxa9 and Meis1 was sufficient for initiating a leukemogenic progenitor self-renewal program (Armstrong et al, 2002; Ayton \& Cleary, 2003; Ferrando et al, 2003; Huang et al, 2012; De Braekeleer et al, 2014; Garcia-Cuellar et al, 2016; Collins \& Hess, 2016a). C/EBPa is also essential in Hoxa9/Meis1induced leukemic transformation (Collins et al, 2014), yet HOXA9/ HOXA10/Meis1 were only partially down-regulated in the Cebpa/Cebpb $\mathrm{dKO}$ C/EBP $\varepsilon^{+}$cells. We believe that the expression of resident C/EBPE in the $\mathrm{dKO}$ cells compensated further down-regulation beyond a lower limit, thereby functionally substituting for the absence of Cebpa/Cebpb, whereas cells that failed to express C/EBPE were lost.
Accordingly, the most strongly affected genes in the dKO cells may therefore represent secondary functional targets, such as autocrine IGF1 stimulation, which contributed to accelerated growth and prevention of apoptosis, but may not be entirely central to leukemic transformation.

Previous research suggesting a C/EBP $\alpha$-induced epigenetic state that is subsequently maintained by the MLL-ENL oncoprotein (Ohlsson et al, 2014; Roe \& Vakoc, 2014) is contrasted by various lines of evidence suggesting that, in higher organisms, maintenance of the epigenetic state relies on the continuous presence of priming master regulatory transcription factors (Blau et al, 1985; Blau \& Baltimore, 1991; Holmberg \& Perlmann, 2012). Our data support the latter concept and suggest a prominent role for distinct C/EBP family members and isoforms in MLL-ENL transformation, reflecting a type of lineage- and differentiation state-specific nononcogenic dependence on transformation. Pharmacological interference with the non-oncogenic C/EBP dependence on acutely transforming myelomonocytic oncoproteins could potentially extend a future clinical repertoire of treatment regimens with the aim of eradicating devastating infant $\mathrm{AML}$.

\section{Materials and Methods}

\section{Generation of MLL-ENL-transformed cells}

Viral supernatants were produced by transfecting Plat-E cells with pMIGGFP retroviral vector or pMSCV-MLL-ENL construct. Infectious supernatant was collected 48 and $72 \mathrm{~h}$ post-transfection. Mouse embryos ( $13.5 \mathrm{~d}$ ) were dissected and genotyped. Hematopoietic stem and progenitor cells were isolated from the mouse fetal livers and transduced during two consecutive days by centrifugation (twice: $1 \mathrm{~h}, 900 \mathrm{~g}$ ) with viral supernatant and $8 \mu \mathrm{g} / \mathrm{ml}$ hexadimethrine bromide. After the second infection, the cells were recovered in IMDM supplemented with murine IL-3 $(10 \mathrm{ng} / \mathrm{ml}), \mathrm{IL}-6$ (10 ng/ml), and SCF (50 ng/ml) (STEMCELL Technologies). Infected cells were selected with $500 \mu \mathrm{g} / \mathrm{ml}$ G418 (Sigma-Aldrich). After 14-d antibiotic selection, the cells were seeded in MethoCult M3434 (STEMCELL Technologies). Colonies formed from single cells were isolated, expanded, and analyzed. Flow cytometry was performed with LSR II or Fortessa machines (Becton Dickinson). The following antibodies from BioLegend or eBioscience were used: CD11b (M1/70), CD117 (2B8), Ly6C (AL-21), Ly6G (1A8), CD115 (AFS98), Sca1 (D7), and CD64 (X54-5/7.1).

\section{Cell culture}

The MLL-ENL-transformed cell lines were cultured in IMDM (10\% FCS, 1\% penicillin/streptomycin [Gibco]) supplemented with $10 \mathrm{ng} /$ $\mathrm{ml}$ mouse IL-3 (STEMCELL Technologies). Cells were split every 2-3 d to $1 \times 10^{5}$ cells $/ \mathrm{ml}$. Plat-E cells were cultured in DMEM (10\% FCS, $1 \%$ Hepes, and $1 \%$ penicillin/streptomycin [Gibco]). Transient transfections were performed using polyethylenimine (Polysciences) according to the manufacturer's protocol.

\section{TAT-Cre treatment and selection of recombinant clones}

Before the treatment, TAT-Cre recombinase (Millipore) was diluted to a final concentration of $4 \mu \mathrm{M}$ in IMDM and filtered $(0.2-\mu \mathrm{m}$ 
low-protein-binding filter). Cell pellets of $4 \times 10^{5} \mathrm{MLL}$-ENL-transformed cells were resuspended in $1 \mathrm{ml}$ TAT-Cre solution, transferred to a 24-well plate, and incubated at $37^{\circ} \mathrm{C}$ for $20 \mathrm{~h}$. The cells were washed with PBS and seeded in MethoCult M3134 (STEMCELL Technologies) supplemented with $10 \mathrm{ng} / \mathrm{ml}$ mouse IL-3. Colonies were transferred to liquid medium, expanded, and analyzed by PCR for excision of Cebpa and/or Cebpb.

\section{Retroviral transduction with C/EBP isoforms, GFP vector control, or BFP Cas9-sgRNA C/EBPE}

Viral supernatants were produced by transfecting Plat-E cells with empty pMIG-GFP retroviral vector or pMIG-GFP constructs containing p42, p30, LAP*, LAP, or LIP, or pMSCV-BFP constructs containing Cas9 and sgRNAs targeting Cebpe. The cells were centrifuged with infectious supernatant collected $72 \mathrm{~h}$ after transfection and $8 \mu \mathrm{g} / \mathrm{ml}$ hexadimethrine bromide ( $1 \mathrm{~h}, 900 \mathrm{~g})$, and left for recovery overnight.

\section{Plasmids and retroviral constructs}

The MLL-ENL retroviral construct has been described previously (Slany et $\mathrm{al}, 1998)$. C/EBP $\alpha, \beta$ isoform expression constructs, amino acid sequence, and retroviral construction have been published previously and are available on request (Kowenz-Leutz et al, 1994; Stoilova et al, 2013; Cirovic et al, 2017). pMSCV_Cas9-2A-GFP-sgRNA (\#124889; Addgene) and pMSCV-U6sgRNA(BbsI)-PGKpuro2A-BFP (\#102796; Addgene) were purchased (Li et al, 2016; Henriksson et al, 2019). The T2A-GFP fragment of the pMSCV GFP-Cas9-containing construct was excised by $\mathrm{BamHI} /$ Notl restriction digest. The T2A-BFP marker of pMSCVU6sgRNA(BbsI)-PGKpuro2A-BFP was amplified by PCR and cloned as a BamHI/ Notl fragment into the pMSCV Cas9 construct. BFP primer: 5' BamHI_T2A-BFP 5'-CGCGGATCCGGAGAGGGCAGAGGAAGTCTC-3'; 5'BFP-Notl: 5'-ATAGTTTAGCGGCCGCTCAATTAAGCTTGTGCCC-3'.

Cebpe sgRNAs were selected using CrispRGold (https:// crisprgold. mdc-berlin.de) and CRISPOR (http://crispor.tefor.net). The sgRNAs were cloned by Bbsl into the pMSCV_Cas9-2A-BFP-sgRNA vector. The C/EBPE sgRNA oligos used were 5'-CTTACCTTGAGGACACGCAA-3', 5' AGGGATAGGCGAATGGCCGA-3', 5' -CTCGTTTCCTCACTACCTGC-3', and 5'CGCACTCATAGTAGGTCCCG-3'.

\section{Analysis of C/EBP $\varepsilon$ genome editing by CRISPR/Cas9 and C/EBPE sgRNAs}

Total DNA was isolated from single cell clones using QuickExtract DNA Extraction Solution (Epicentre). Cebpe genomic exon 1 was amplified by PCR, the fragments were purified (Invisorb \#1020300300; Invitek), and analyzed by Sanger sequencing (LGC Genomics). The edited sequences were analyzed using modified ICE software (Hsiau et al, 2018 Preprint), available from Synthego (https://www.synthego.com/products/bioinformatics/crispr-analysis). The PCR primers used for Cebpe exon 1 analysis were 5'-CAGGACACAGCCGAGTTCTA-3' and 5'-CTAGGGCAAATCTAGGACCG-3'.

\section{Genotyping}

Total DNA was isolated using QuickExtract DNA Extraction Solution (Epicentre). Cebpa excision was evaluated by two separate PCR for the Cebpa flox allele and Cebpa deletion. The Cebpa flox allele primers were $5^{\prime}$-TGGCCTGGAGACGCAATGA-3' and 5'-CGCAGAGATTGTGCGTCTTT$3^{\prime}$; the expected product was $269 \mathrm{bp}$. The Cebpa deletion primers were: 5'-GCCTGGTAAGCCTAGCAATCCT-3' and 5'-TGGAAACTTGGGTGGGTGT-3'; the expected product was $380 \mathrm{bp}$. Cebpb excision was determined by competitive PCR using the following primers: $5^{\prime}$-GAGCCACCGCGTCCTCCAGC-3', 5'-GGTCGGTGCGCGTCATTGCC-3', and 5'-AGCAGAGCTGCCCCGGCAAA-3'; the reaction produced bands of $253 \mathrm{bp}$ for the flox allele and $610 \mathrm{bp}$ for the deleted allele.

\section{Immunoblotting}

Total protein lysates were prepared by lysing fresh cell pellets with $0.5 \mathrm{M} \mathrm{NaOH}$ with subsequent neutralization with $0.5 \mathrm{M} \mathrm{HCl}$. The samples were sonicated, mixed with SDS sample buffer and glycerol, and heated $\left(3 \mathrm{~min}\right.$ at $\left.95^{\circ} \mathrm{C}\right)$. After centrifugation, the protein lysates were separated by electrophoresis and transferred to a nitrocellulose membrane using a Trans-Blot Turbo System (Bio-Rad). Protein signals were detected after incubation with antibodies against C/EBP $\alpha$ (14AA; Santa Cruz Biotechnology), C/EBP $\beta$ (C-19; Santa Cruz Biotechnology), C/EBPS (C-22; Santa Cruz Biotechnology), C/ EBPE (NBP1-85446; Novus Biologicals), Flag-M2 (F-1804; Sigma-Aldrich), and GAPDH (ab9484; Abcam).

\section{Apoptosis assay}

The level of apoptosis was determined with a FITC-Annexin V Apoptosis Detection Kit I (BD Pharmingen). After washing twice with cold PBS, $1 \times 10^{6}$ cells were resuspended in $1 \mathrm{ml} 1 \times$ binding buffer. Cell suspension $(100 \mu \mathrm{l})$ was transferred to a new tube and mixed with $5 \mu \mathrm{l} \mathrm{FITC-annexin} \mathrm{V.} \mathrm{The} \mathrm{samples} \mathrm{were} \mathrm{incubated} \mathrm{for} 15 \mathrm{~min}$ at room temperature in the dark. Afterward, $5 \mu \mathrm{l}$ 7-AAD (BD Pharmingen) was added and the samples were subsequently analyzed using an LSR II flow cytometer (Becton Dickinson).

\section{Proliferation and metabolism assays}

The MLL-ENL-transformed cells were seeded at $5 \times 10^{4}$ cells per well in $100 \mu \mathrm{l}$ complete IMDM in 96-well plates in triplicate. The cells were incubated for 48,72 , or $96 \mathrm{~h}$ at $37^{\circ} \mathrm{C}$. The cell proliferation reagent WST-1 (10 $\mu \mathrm{l} /$ well; Roche) was added, gently mixed, and incubated at $37^{\circ} \mathrm{C}$ for $1 \mathrm{~h}$. The absorbance of the samples was measured at $450 \mathrm{~nm}$ using an iMark microplate reader (Bio-Rad). A murine IGF-1 ELISA kit (BGK9PU89; BioGems) was applied according to the manufacturer's protocol. For the CFSE proliferation assay, $1 \times$ $10^{6}$ cells were resuspended in $1 \mathrm{ml} 5 \mu \mathrm{M}$ CFSE solution (BioLegend) for $20 \mathrm{~min}$ in the dark at room temperature. Afterward, the reaction was quenched using $5 \mathrm{ml}$ cell culture medium plus 10\% FCS. The cells were washed and cultured for the indicated time.

\section{Colony formation assay, determination of colony size and number, serial replating}

The MLL-ENL-transformed cells were added to complete (10\% FCS, $1 \%$ penicillin/streptomycin [Gibco]) and IL-3-supplemented (10 ng/ $\mathrm{ml}$ ) MethoCult 3134 (STEMCELL Technologies) at a final concentration of 5,000 cells per $\mathrm{mL}$ (if not indicated otherwise). The cell mix $(1 \mathrm{ml})$ was seeded in six-well meniscus-free plates (SmartDish; 
STEMCELL Technologies) in triplicate. High-resolution microscopic scans were taken after 7, 10, and $14 \mathrm{~d}$ using an EVOS imaging system (Thermo Fisher Scientific). The number, size, and approximate cell numbers of the colonies were calculated using Image software with the ColonyArea plugin. Serial replating experiments were set up with 5,000 cells per $\mathrm{mL}$ in MethoCult 3134 supplemented with IL-3 (10 ng/ml), IL-6 (5 ng/ml), SCF $(25 \mathrm{ng} / \mathrm{ml})$ and GM-CSF $(5 \mathrm{ng} / \mathrm{ml})$. After $7 \mathrm{~d}$ in culture, colony numbers were determined using the EVOS imaging system, colonies were harvested by centrifugation in culture medium, cell numbers and viability were determined, and comparable numbers of cells were re-seeded in Methocult 3134 under the conditions described above.

\section{ATAC-seq}

To prepare the ATAC-seq libraries, 50,000 cells were sorted into $500 \mu \mathrm{l}$ PBS. The libraries were prepared as previously described (Buenrostro et al, 2013), with slight modifications (Lara-Astiaso et al, 2014). Briefly, the cells were lysed with $25 \mu \mathrm{l}$ cold lysis buffer (10 mM Tris-HCl [pH 7.4], 10 $\mathrm{mM} \mathrm{MgCl}$, and $0.1 \%$ Igepal CA-630) and the nuclei were pelleted by centrifugation for $25 \mathrm{~min}$ at $4^{\circ} \mathrm{C}$ and $500 \mathrm{~g}$ in a swing rotor with low acceleration and brake settings. The pellet was resuspended in $25 \mu \mathrm{l}$ reaction mix containing $2 \mu \mathrm{l}$ Tn5 transposase and $12.5 \mu \mathrm{l}$ TD buffer (Nextera DNA library preparation kit; Illumina), and incubated at $37^{\circ} \mathrm{C}$ for $1 \mathrm{~h}$. Next, $5 \mu \mathrm{l}$ cleanup buffer ( $900 \mathrm{mM} \mathrm{NaCl}, 30 \mathrm{mM}$ EDTA) with $2 \mu \mathrm{l} 5 \%$ SDS and $2 \mu \mathrm{l}$ proteinase $\mathrm{K}$ (NEB) were added, and the samples were incubated at $40^{\circ} \mathrm{C}$ for $30 \mathrm{~min}$. Subsequently, the DNA was purified using AMPure XP beads (Beckman Coulter) and PCR-amplified with KAPA HiFi HotStart ReadyMix (Kapa Biosystems) and indexing primers published previously (Buenrostro et al, 2013). Then, the DNA library fragments were selected for $<600$-bp fragments and purified using AMPure XP beads. The concentration and fragment size of the final libraries were measured using a Qubit fluorometer (Life Technologies) and TapeStation (Agilent Technologies). The samples were sequenced with an average of 25 million reads per sample using a NextSeq 500 system (Illumina).

\section{Sequencing data analysis}

RNA-seq libraries were prepared using Illumina TruSeq stranded mRNA kit starting with 500 ng of input total RNA. Libraries included dual indices and were equimolar pooled. Paired-end $76 \mathrm{nt}$ sequencing was performed on Illumina NextSeq 500 High Output v.2 flowcell. RNAseq samples were aligned to the reference genome (mm10) using STAR (Dobin et al, 2013). Expression was quantified using HTSeq (Anders et al, 2015); downstream analysis was done with DESeq2 using the included normalization strategy (for details see Love et al [2014]) and a Benjamini-Hochberg-corrected P-value of 0.05 as a significance cutoff. Alterations in function induced by the different expression patterns in the conditions were assessed using GSEA using gene sets by MSigDB (Liberzon et al, 2011) and Camera (Wu \& Smyth, 2012). ATACseq samples were preprocessed with PiGx pipelines (Wurmus et al, 2018), including alignment to a reference with Bowtie 2 (Langmead \& Salzberg, 2012), to genome version mm10 and peak-calling using MACS (Zhang et al, 2008). Differential peaks were detected with DiffBind (2.14) using a corrected P-value of 0.05 as a cutoff (Ross-Ines et al, 2012). Known motif detection was performed using findMotifsGenome.pl in HOMER (v4.10.3) (\$ findMotifsGenome.pl XXX.bed mm10 homer/ -size
200 -mask) (Heinz et al, 2010). The set of genomic regions used for motif discovery comprises the regions of those genes, that exhibited both, re-established gene expression (uncorrected $P$-value $<0.05$ ) and restored chromatin status (corrected $P$-value $<0.05$ ) in dKO-LAP* cells toward the $\mathrm{WT}^{\mathrm{FL}}$ status.

\section{Data Availability}

Data generated during this study have been deposited in Gene Expression Omnibus with the accession codes GSE153622, GSE153623, and GSE153624.

\section{Supplementary Information}

Supplementary Information is available at https://doi.org/10.26508/lsa. 202000709.

\section{Acknowledgements}

Reagents were kindly provided by Klaus Rajewsky. We thank Hans-Peter Rahn and Linh Thuy Nguyen for help with flow cytometry; Martin Janz, Stephan Mathas (all Max-Delbrueck-Center for Molecular Medicine, MDC, Berlin), and Karl-Heinz Seeger (Charité, Berlin) for discussion; and Ralph Kühn (MDC) for help with CRISPR data analysis. D Dörr was funded by the International MDC-PhD program and KZimmermann by a grant from the DFG, CRC167, and B11. A Mildner was funded by a Heisenberg Fellowship from the Deutsche Forschungsgemeinschaft (DFG and MI1328).

\section{Author Contributions}

R Wesolowski: data curation and writing-original draft, review, and editing.

E Kowenz-Leutz: resources, data curation, formal analysis, validation, investigation, methodology, and writing-review and editing. K Zimmermann: data curation, software, formal analysis, and writing-review and editing.

D Dörr: investigation, methodology, and writing-review and editing. M Hofstätter: validation, investigation, and methodology.

RK Slany: resources, methodology, and writing-review and editing. A Mildner: data curation, formal analysis, investigation, and writing-review and editing.

A Leutz: conceptualization, resources, data curation, formal analysis, supervision, funding acquisition, validation, investigation, visualization, methodology, project administration, and writing-original draft, review, and editing.

\section{Conflict of Interest Statement}

The authors declare that they have no conflict of interest.

\section{References}

Akagi T, Thoennissen NH, George A, Crooks G, Song JH, Okamoto R, Nowak D, Gombart AF, Koeffler HP (2010) In vivo deficiency of both C/EBPbeta 
and C/EBPepsilon results in highly defective myeloid differentiation and lack of cytokine response. PLoS One 5: e15419. doi:10.1371/ journal.pone.0015419

Anders S, Pyl PT, Huber W (2015) HTSeq: A Python framework to work with high-throughput sequencing data. Bioinformatics 31: 166-169. doi:10.1093/bioinformatics/btu638

Angerer ND, Du Y, Nalbant D, Williams SC (1999) A short conserved motif is required for repressor domain function in the myeloid-specific transcription factor CCAAT/enhancer-binding protein epsilon. J Biol Chem 274: 4147-4154. doi:10.1074/jbc.274.7.4147

Armstrong SA, Staunton JE, Silverman LB, Pieters R, den Boer ML, Minden MD, Sallan SE, Lander ES, Golub TR, Korsmeyer SJ (2002) MLL translocations specify a distinct gene expression profile that distinguishes a unique leukemia. Nat Genet 30: 41-47. doi:10.1038/ng765

Ayton PM, Cleary ML (2003) Transformation of myeloid progenitors by MLL oncoproteins is dependent on Hoxa7 and Hoxa9. Genes Dev 17: 2298-2307. doi:10.1101/gad.1111603

Blau HM, Baltimore D (1991) Differentiation requires continuous regulation. J Cell Biol 112: 781-783. doi:10.1083/jcb.112.5.781

Blau HM, Pavlath GK, Hardeman EC, Chiu CP, Silberstein L, Webster SG, Miller SC, Webster C (1985) Plasticity of the differentiated state. Science 230: 758-766. doi:10.1126/science.2414846

Brown RA, Byersdorfer CA (2017) Using tat-cre to generate ex-vivo gene knockouts in T-cells. J Immunol 198: 157.121.

Buenrostro JD, Giresi PG, Zaba LC, Chang HY, Greenleaf WJ (2013) Transposition of native chromatin for fast and sensitive epigenomic profiling of open chromatin, DNA-binding proteins and nucleosome position. Nat Methods 10: 1213-1218. doi:10.1038/nmeth.2688

Chen L, Deshpande AJ, Banka D, Bernt KM, Dias S, Buske C, Olhava EJ, Daigle SR, Richon VM, Pollock RM, et al (2013) Abrogation of MLL-AF10 and CALM-AF10-mediated transformation through genetic inactivation or pharmacological inhibition of the H3K79 methyltransferase Dot1L. Leukemia 27: 813-822. doi:10.1038/leu.2012.327

Cirovic B, Schonheit J, Kowenz-Leutz E, Ivanovska J, Klement C, Pronina N Begay V, Leutz A (2017) C/EBP-induced transdifferentiation reveals granulocyte-macrophage precursor-like plasticity of B cells. Stem Cell Reports 8: 346-359. doi:10.1016/j.stemcr.2016.12.015

Collins C, Wang J, Miao H, Bronstein J, Nawer H, Xu T, Figueroa M, Muntean AG, Hess JL (2014) C/EBPalpha is an essential collaborator in Hoxa9/ Meis1-mediated leukemogenesis. Proc Natl Acad Sci U S A 111: 9899-9904. doi:10.1073/pnas.1402238111

Collins CT, Hess JL (2016a) Deregulation of the HOXA9/MEIS1 axis in acute leukemia. Curr Opin Hematol 23: 354-361. doi:10.1097/moh. 0000000000000245

Collins CT, Hess JL (2016b) Role of HOXA9 in leukemia: Dysregulation, cofactors and essential targets. Oncogene 35: 1090-1098. doi:10.1038/ onc. 2015.174

Cozzio A, Passegue E, Ayton PM, Karsunky H, Cleary ML, Weissman IL (2003) Similar MLL-associated leukemias arising from self-renewing stem cells and short-lived myeloid progenitors. Genes Dev 17: 3029-3035. doi:10.1101/gad.1143403

Daigle SR, Olhava EJ, Therkelsen CA, Majer CR, Sneeringer CJ, Song J, Johnston LD, Scott MP, Smith JJ, Xiao Y, et al (2011) Selective killing of mixed lineage leukemia cells by a potent small-molecule DOT1L inhibitor Cancer Cell 20: 53-65. doi:10.1016/j.ccr.2011.06.009

De Braekeleer E, Douet-Guilbert N, Basinko A, Le Bris MJ, Morel F, De Braekeleer M (2014) Hox gene dysregulation in acute myeloid leukemia. Future Oncol 10: 475-495. doi:10.2217/fon.13.195

Dobin A, Davis CA, Schlesinger F, Drenkow J, Zaleski C, Jha S, Batut P, Chaisson M, Gingeras TR (2013) STAR: Ultrafast universal RNA-seq aligner. Bioinformatics 29: 15-21. doi:10.1093/bioinformatics/bts635
El-Brolosy MA, Stainier DYR (2017) Genetic compensation: A phenomenon in search of mechanisms. PLoS Genet 13: e1006780. doi:10.1371/ journal.pgen.1006780

Ferrando AA, Armstrong SA, Neuberg DS, Sallan SE, Silverman LB, Korsmeyer SJ, Look AT (2003) Gene expression signatures in MLL-rearranged T-lineage and B-precursor acute leukemias: Dominance of HOX dysregulation. Blood 102: 262-268. doi:10.1182/blood-2002-10-3221

Garcia-Cuellar MP, Buttner C, Bartenhagen C, Dugas M, Slany RK (2016) Leukemogenic MLL-ENL fusions induce alternative chromatin states to drive a functionally dichotomous group of target genes. Cell Rep 15: 310-322. doi:10.1016/j.celrep.2016.03.018

Goardon N, Marchi E, Atzberger A, Quek L, Schuh A, Soneji S, Woll P, Mead A Alford KA, Rout R, et al (2011) Coexistence of LMPP-like and GMP-like leukemia stem cells in acute myeloid leukemia. Cancer Cell 19: 138-152. doi:10.1016/j.ccr.2010.12.012

Heinz S, Benner C, Spann N, Bertolina E, Lin YC, Laslo P, Cheng JX, Murre C, Singh H, Glass CK (2010) Simple combinations of lineage-determining transcription factors prime cis-regulatory elements required for macrophage and B cell identities. Mol Cell 38: 576-689. doi:10.1016/ j.molcel.2010.05.004

Heng TS, Painter MW (2008) The immunological genome project: Networks of gene expression in immune cells. Nat Immunol 9: 1091-1094. doi:10.1038/ni1008-1091

Henriksson J, Chen X, Gomes T, Ullah U, Meyer KB, Miragaia R, Duddy G, Pramanik J, Yusa K, Lahesmaa R, et al (2019) Genome-wide CRISPR screens in $T$ helper cells reveal pervasive crosstalk between activation and differentiation. Cell 176: 882-896.e18. doi:10.1016/ j.cell.2018.11.044

Hirai H, Zhang P, Dayaram T, Hetherington CJ, Mizuno S, Imanishi J, Akashi K Tenen DG (2006) C/EBPbeta is required for "emergency" granulopoiesis. Nat Immunol 7: 732-739. doi:10.1038/ni1354

Holmberg J, Perlmann T (2012) Maintaining differentiated cellular identity. Nat Rev Genet 13: 429-439. doi:10.1038/nrg3209

Hsiau T, Maures T, Waite K, Yang J, Kelso R, Holden K, Stoner R (2018) Inference of CRISPR Edits from sanger trace data. BioRxiv 251082. doi:10.1101/ 251082 (Preprint posted August 10, 2019).

Huang Y, Sitwala K, Bronstein J, Sanders D, Dandekar M, Collins C, Robertson G, MacDonald J, Cezard T, Bilenky M, et al (2012) Identification and characterization of Hoxa9 binding sites in hematopoietic cells. Blood 119: 388-398. doi:10.1182/blood-2011-03-341081

Huntly BJ, Shigematsu H, Deguchi K, Lee BH, Mizuno S, Duclos N, Rowan R, Amaral S, Curley D, Williams IR, et al (2004) MOZ-TIF2, but not BCR-ABL, confers properties of leukemic stem cells to committed murine hematopoietic progenitors. Cancer Cell 6: 587-596. doi:10.1016/ j.ccr.2004.10.015

Jaitin DA, Weiner A, Yofe I, Lara-Astiaso D, Keren-Shaul H, David E, Salame TM, Tanay A, van Oudenaarden A, Amit I (2016) Dissecting immune circuits by linking CRISPR-pooled screens with single-cell RNA-seq. Cell 167: 1883-1896.e15. doi:10.1016/j.cell.2016.11.039

Jamieson CH, Ailles LE, Dylla SJ, Muijtjens M, Jones C, Zehnder JL, Gotlib J, Li K, Manz MG, Keating A, et al (2004) Granulocyte-macrophage progenitors as candidate leukemic stem cells in blast-crisis CML. N Engl J Med 351: 657-667. doi:10.1056/nejmoa040258

Jiang Y, Qian F, Bai X, Liu Y, Wang Q, Ai B, Han X, Shi S, Zhang J, Li X, et al (2019) SEdb: A comprehensive human super-enhancer database. Nucleic Acids Res 47: D235-D243. doi:10.1093/nar/gky1025

Johnson PF (2005) Molecular stop signs: Regulation of cell-cycle arrest by C/ EBP transcription factors. J Cell Sci 118: 2545-2555. doi:10.1242/ jcs.02459

Jones LC, Lin ML, Chen SS, Krug U, Hofmann WK, Lee S, Lee YH, Koeffler HP (2002) Expression of C/EBP $\beta$ from the $C /$ ebp $\alpha$ gene locus is sufficient for normal hematopoiesis in vivo. Blood 99: 2032-2037. doi:10.1182/ blood.v99.6.2032 
Kowenz-Leutz E, Twamley G, Ansieau S, Leutz A (1994) Novel mechanism of C/EBP beta (NF-M) transcriptional control: Activation through derepression. Genes Dev 8: 2781-2791. doi:10.1101/gad.8.22.2781

Krivtsov AV, Armstrong SA (2007) MLL translocations, histone modifications and leukaemia stem-cell development. Nat Rev Cancer 7: 823-833. doi:10.1038/nrc2253

Krivtsov AV, Figueroa ME, Sinha AU, Stubbs MC, Feng Z, Valk PJ, Delwel R, Dohner K, Bullinger L, Kung AL, et al (2013) Cell of origin determines clinically relevant subtypes of MLL-rearranged AML. Leukemia 27: 852-860. doi:10.1038/leu.2012.363

Krivtsov AV, Twomey D, Feng Z, Stubbs MC, Wang Y, Faber J, Levine JE, Wang J, Hahn WC, Gilliland DG, et al (2006) Transformation from committed progenitor to leukaemia stem cell initiated by MLL-AF9. Nature 442: 818-822. doi:10.1038/nature04980

Langmead B, Salzberg SL (2012) Fast gapped-read alignment with Bowtie 2. Nat Methods 9: 357-359. doi:10.1038/nmeth.1923

Lara-Astiaso D, Weiner A, Lorenzo-Vivas E, Zaretsky I, Jaitin DA, David E, KerenShaul H, Mildner A, Winter D, Jung S, et al (2014) Immunogenetics. Chromatin state dynamics during blood formation. Science 345: 943-949. doi:10.1126/science.1256271

Li H, Shi J, Huang NJ, Pishesha N, Natarajan A, Eng JC, Lodish HF (2016) Efficient CRISPR-Cas9 mediated gene disruption in primary erythroid progenitor cells. Haematologica 101: e216-e219. doi:10.3324/ haematol.2015.135723

Liberzon A, Subramanian A, Pinchback R, Thorvaldsdottir H, Tamayo P, Mesirov JP (2011) Molecular signatures database (MSigDB) 3.0. Bioinformatics 27: 1739-1740. doi:10.1093/bioinformatics/btr260

Love MI, Huber W, Anders S (2014) Moderated estimation of fold change and dispersion for RNA-seq data with DESeq2. Genome Biol 15: 550. doi:10.1186/s13059-014-0550-8

Manz MG, Boettcher S (2014) Emergency granulopoiesis. Nat Rev Immunol 14: 302-314. doi:10.1038/nri3660

Nagel R, Semenova EA, Berns A (2016) Drugging the addict: Non-oncogene addiction as a target for cancer therapy. EMBO Rep 17: 1516-1531. doi:10.15252/embr.201643030

Nerlov C (2004) C/EBPalpha mutations in acute myeloid leukaemias. Nat Rev Cancer 4: 394-400. doi:10.1038/nrc1363

Ohlsson E, Hasemann MS, Willer A, Lauridsen FK, Rapin N, Jendholm J, Porse BT (2014) Initiation of MLL-rearranged AML is dependent on C/ EBPalpha. J Exp Med 211: 5-13. doi:10.1084/jem.20130932

Okada Y, Feng Q, Lin Y, Jiang Q, Li Y, Coffield VM, Su L, Xu G, Zhang Y (2005) hDOT1L links histone methylation to leukemogenesis. Cell 121: 167-178. doi:10.1016/j.cell.2005.02.020

Pollak MN, Schernhammer ES, Hankinson SE (2004) Insulin-like growth factors and neoplasia. Nat Rev Cancer 4: 505-518. doi:10.1038/nrc1387

Roe J-S, Mercan F, Rivera K, Pappin DJ, Christopher R, Harbor CS (2016) BET bromodomain inhibition suppresses the functional output of hematopoietic transcription factors in acute myeloid leukemia. Mol Cell 58: 1028-1039. doi:10.1016/j.molcel.2015.04.011

Roe JS, Vakoc CR (2014) C/EBPalpha: Critical at the origin of leukemic transformation. J Exp Med 211: 1-4. doi:10.1084/jem.20132530

Ross-Ines CS, Stark R, Teschendorff AE, Holmes KA, Ali HR, Dunning MJ, Brown GD, Gojis O, Ellis IO, Green AR, et al (2012) Differential oestrogen receptor binding is associated with clinical outcome in breast cancer. Nature 481: 389-393. doi:10.1038/ nature10730

Shilatifard A (2012) The COMPASS family of histone H3K4 methylases: Mechanisms of regulation in development and disease pathogenesis. Annu Rev Biochem 81: 65-95. doi:10.1146/annurev-biochem-051710-134100

Slany RK (2016) The molecular mechanics of mixed lineage leukemia. Oncogene 35: 5215-5223. doi:10.1038/onc.2016.30
Slany RK, Lavau C, Cleary ML (1998) The oncogenic capacity of HRX-ENL requires the transcriptional transactivation activity of ENL and the DNA binding motifs of HRX. Mol Cell Biol 18: 122-129. doi:10.1128/mcb.18.1.122

Smith E, Lin C, Shilatifard A (2011) The super elongation complex (SEC) and MLL in development and disease. Genes Dev 25: 661-672. doi:10.1101/gad.2015411

Solimini NL, Luo J, Elledge SJ (2007) Non-oncogene addiction and the stress phenotype of cancer cells. Cell 130: 986-988. doi:10.1016/ j.cell.2007.09.007

Somervaille TC, Cleary ML (2006) Identification and characterization of leukemia stem cells in murine MLL-AF9 acute myeloid leukemia. Cancer Cell 10: 257-268. doi:10.1016/j.ccr.2006.08.020

Steger J, Fuller E, Garcia-Cuellar MP, Hetzner K, Slany RK (2015) Insulin-like growth factor 1 is a direct HOXA9 target important for hematopoietic transformation. Leukemia 29: 901-908. doi:10.1038/leu.2014.287

Stoilova B, Kowenz-Leutz E, Scheller M, Leutz A (2013) Lymphoid to myeloid cell trans-differentiation is determined by C/EBPbeta structure and post-translational modifications. PLoS One 8: e65169. doi:10.1371/ journal.pone.0065169

Tamura A, Hirai H, Yokota A, Kamio N, Sato A, Shoji T, Kashiwagi T, Torikoshi Y, Miura $\mathrm{Y}$, Tenen DG, et al (2017) C/EBPbeta is required for survival of Ly6C(-) monocytes. Blood 130: 1809-1818. doi:10.1182/blood-2017-03-772962

Wang D, D'Costa J, Civin Cl, Friedman AD (2006) C/EBPalpha directs monocytic commitment of primary myeloid progenitors. Blood 108: 1223-1229. doi:10.1182/blood-2005-12-008763

Wessells J, Yakar S, Johnson PF (2004) Critical prosurvival roles for C/ EBP beta and insulin-like growth factor I in macrophage tumor cells. Mol Cell Biol 24: 3238-3250. doi:10.1128/mcb.24.8.3238-3250.2004

Wu D, Smyth GK (2012) Camera: A competitive gene set test accounting for inter-gene correlation. Nucleic Acids Res 40: e133. doi:10.1093/nar/ gks461

Wurmus R, Uyar B, Osberg B, Franke V, Gosdschan A, Wreczycka K, Ronen J, Akalin A (2018) PiGx: Reproducible genomics analysis pipelines with GNU guix. Gigascience 7: giy123. doi:10.1093/gigascience/giy123

Ye M, Zhang H, Yang H, Koche R, Staber PB, Cusan M, Levantini E, Welner RS, Bach CS, Zhang J, et al (2015) Hematopoietic differentiation is required for initiation of acute myeloid leukemia. Cell Stem Cell 17: 611-623. doi:10.1016/j.stem.2015.08.011

Zahnow CA (2002) CCAAT/enhancer binding proteins in normal mammary development and breast cancer. Breast Cancer Res 4: 113-121. doi:10.1186/bcr428

Zhang H, Alberich-Jorda M, Amabile G, Yang H, Staber PB, DiRuscio A, Welner RS, Ebralidze A, Zhang J, Levantini E, et al (2013) Sox4 is a key oncogenic target in C/EBP $\alpha$ mutant acute myeloid leukemia. Cancer Cell 24: 575-588. doi:10.1016/j.ccr.2013.09.018

Zhang P, Iwasaki-Arai J, Iwasaki H, Fenyus ML, Dayaram T, Owens BM, Shigematsu H, Levantini E, Huettner CS, Lekstrom-Himes JA, et al (2004) Enhancement of hematopoietic stem cell repopulating capacity and self-renewal in the absence of the transcription factor C/EBP alpha. Immunity 21: 853-863. doi:10.1016/j.immuni.2004.11.006

Zhang Y, Liu T, Meyer CA, Eeckhoute J, Johnson DS, Bernstein BE, Nusbaum C, Myers RM, Brown M, Li W, et al (2008) Model-based analysis of ChIPseq (MACS). Genome Biol 9: R137. doi:10.1186/gb-2008-9-9-r137

Zhong X, Prinz A, Steger J, Garcia-Cuellar MP, Radsak M, Bentaher A, Slany RK (2018) HoxA9 transforms murine myeloid cells by a feedback loop driving expression of key oncogenes and cell cycle control genes. Blood Adv 2: 3137-3148. doi:10.1182/bloodadvances.2018025866

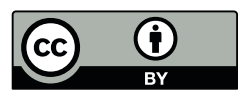

License: This article is available under a Creative Commons License (Attribution 4.0 International, as described at https://creativecommons.org/ licenses/by/4.0/). 